NBER WORKING PAPER SERIES

\title{
BACK TO BASICS: BASIC RESEARCH SPILLOVERS, INNOVATION POLICY AND GROWTH
}

\author{
Ufuk Akcigit \\ Douglas Hanley \\ Nicolas Serrano-Velarde \\ Working Paper 19473 \\ http://www.nber.org/papers/w19473 \\ NATIONAL BUREAU OF ECONOMIC RESEARCH \\ 1050 Massachusetts Avenue \\ Cambridge, MA 02138 \\ September 2013, Revised March 2017
}

We thank the seminar and conference participants at UCLA, University of Pennsylvania, Wharton, World Bank, AEA Meetings, Canadian Macroeconomics Study Group, Centre for Business Taxation Symposium (Oxford), IIO Conference, Bank of Italy, Industry and Labor Market Dynamics (Barcelona), NBER Productivity Lunch Seminar, SKEMA Workshop on Economic Growth, Structural Approaches to Productivity and Industrial Dynamics (Rome), and Turkish Central Bank for their insights. Akcigit gratefully acknowledges financial support from the Alfred P. Sloan Foundation, the Ewing Marion Kauffman Foundation, and the National Science Foundation. Serrano-Velarde gratefully acknowledges financial support from the ESRC (Grant No RES-060-25-0033). The views expressed herein are those of the authors and do not necessarily reflect the views of the National Bureau of Economic Research.

NBER working papers are circulated for discussion and comment purposes. They have not been peer-reviewed or been subject to the review by the NBER Board of Directors that accompanies official NBER publications.

(C) 2013 by Ufuk Akcigit, Douglas Hanley, and Nicolas Serrano-Velarde. All rights reserved. Short sections of text, not to exceed two paragraphs, may be quoted without explicit permission provided that full credit, including $(\odot$ notice, is given to the source. 
Back to Basics: Basic Research Spillovers, Innovation Policy and Growth Ufuk Akcigit, Douglas Hanley, and Nicolas Serrano-Velarde

NBER Working Paper No. 19473

September 2013, Revised March 2017

JEL No. L78,O31,O38,O40,O43,O47

\section{ABSTRACT}

This paper introduces a general equilibrium model of endogenous technical change through basic and applied research. Basic research differs from applied research in the nature and the magnitude of the generated spillovers. We propose a novel way of empirically identifying these spillovers and embed them in a framework with private firms and a public research sector. After characterizing the equilibrium, we estimate our model using micro-level data on research expenditures by French firms. Our key finding is that standard innovation policies (e.g., uniform $\mathrm{R} \& \mathrm{D}$ tax credits) can accentuate the dynamic misallocation in the economy by oversubsidizing applied research. Policies geared towards public basic research and its transmission to the private sector are significantly welfare improving.

Ufuk Akcigit

Department of Economics

University of Chicago

1126 East 59th Street

Saieh Hall, Office 403

Chicago, IL 60637

and NBER

uakcigit@uchicago.edu

Douglas Hanley

Department of Economics, University of Pennsylvania

3718 Locust Walk, \#160

Philadelphia, PA 19104

dohan@as.pitt.edu
Nicolas Serrano-Velarde

Bocconi University

Via Roentgen 1

20135 Milan

Italy

nicolas.serranovelarde@unibocconi.it 


\section{Introduction}

Fostering economic growth is one of the primary objectives of economists and policymakers. The amount of resources invested in research is often at the heart of the debate regarding how to best achieve this. Less well known, however, is what role the composition of research plays in determining growth, particularly when considering the breakdown between basic and applied research. In this paper, we aim to fill this gap by studying the differential effects of basic versus applied research on economic growth.

The distinction between basic and applied research is economically important and relates to the breadth of the scientific examination being undertaken. According to the NSF, basic research investment refers to a "systematic study to gain more comprehensive knowledge or understanding of the subject under study without specific applications in mind." Conversely, applied research is defined as a "systematic study to gain knowledge or understanding to meet a specific, recognized need." Many policy reports, most recently the Economic Report of the President (JEC, 2010, 2016), argue that basic research is underfunded both by private and public entities.

Figure 1: Composition of Research Investment in FRANCE AND THE US

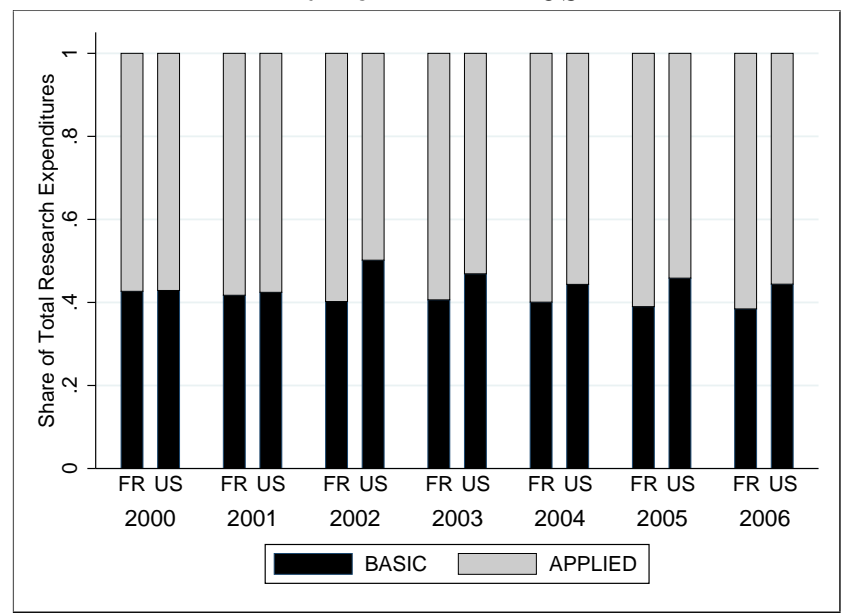

Figure 2: Basic Research Intensity AND Number OF INDUSTRIES

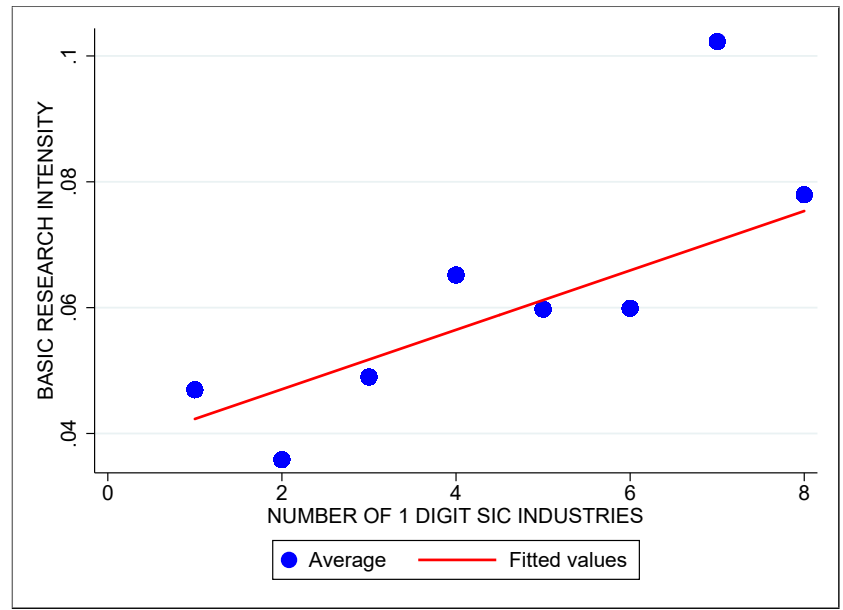

Notes: Figure 1 plots the composition of total research spending for the US and France. The data for the US come from the National Science Foundation, Division of Science Resources Statistics (NSF/SRS), while the data for France come from the French Ministry of Research. Figure 2 uses 13,708 firm-year observations from French firm level data for the period 2000-2006. The dependent variable is the ratio of total firm investment in basic research divided by total firm investment in applied research. The red line represents a linear fit of the firm-year observations, after controlling for firm size (log employment). See Section 3.1 for further details.

Three empirical features of basic and applied research are of special importance. First, in countries such as France and the US, almost half of total research investment is allocated to basic research (see Figure 1). Second, contrary to conventional wisdom, a significant share of basic scientific research involves the private sector. In France almost $15 \%$ of total basic research in the economy is undertaken by the private sector. Similarly for the US economy, Howitt (2000), estimates that around $22 \%$ of all basic research during the period 1993-1997 was performed by private enterprises. Finally, there are 
significant differences in the incentives of firms to invest into basic research. Figure 2 plots the ratio of basic to applied research according to the multi-industry presence of firms for a sample of French firms between 2000 and 2006. The figure suggests that investment into basic research increases as the scope of a firm's activities expands, even after controlling for firm size. These stylized facts suggest that ignoring the composition of research investment and the differential incentives behind each of them might prevent economists and policymakers from designing the most effective policies for productivity growth.

Despite clear empirical importance and considerable policy interest, the differential nature of the roles played by basic and applied research in the growth process is still relatively unexplored, and many related questions remain to be answered: How sizable are the spillovers from basic research? What are the potential inefficiencies in a competitive economy, and what are the appropriate government policies to mitigate them and promote economic growth? This paper attempts to answer these important questions.

In order to understand the potential inefficiencies in research investment and to design appropriate industrial policies to address them, it is necessary to adopt a structural framework that explicitly models the incentives of private and public entities for the different types of research. We propose a general equilibrium, multi-industry framework with private firms and a public research sector. In our model, basic research has two distinct features relative to applied research. First, it generates spillovers that affect subsequent innovations both within and across industries. Applied research, on the other hand, only generates incremental innovations within a targeted industry. Second, the potential returns from basic research depend on whether it was generated in the private or the public sector. In line with the "Ivory Tower" theory of academic research, basic research by private firms in our model will turn into consumer products faster than that undertaken by public research labs.

To highlight the key economic forces, we first consider a benchmark economy with tractable functional forms, characterize the dynamic equilibrium analytically, and discuss the resulting dynamics and inefficiencies. Our ultimate goal in this paper is to undertake a quantitative investigation of the impacts of various innovation policies on the aggregate economy. As such, we then generalize our benchmark framework to allow for greater quantitative flexibility and estimate the structural parameters.

We estimate the structural parameters of our model using French firm-level data for the period 2000-2006. Information about research investment comes from the annual R\&D Survey conducted by the French Ministry of Research. The advantage of this data is that it includes information on the basic and applied research expenditures of firms. To measure the breadth of a firm's activities we combine two datasets ("Enquete Liaisons Financieres" (LIFI), "Enquete Annuelle des Entreprises" (EAE)) that allow us to precisely identify a firm's links to different industries not only through product lines within the same firm, but also through their ownership links. Finally we use the balance sheet data from these firms to measure firm dynamics and NBER patent citation data to measure the quality of innovation. The final sample is composed of 13,708 firm-year observations.

These features of our data allow us to identify and estimate the key spillovers involved in each 
type of research. We identify the cross-industry spillovers associated with basic research through the investment choices of multi-industry firms. Consistent with our model, we observe that investment into basic research increases as the scope of a firm's activities expands. The intuition is that as the range of a firm's products and industries becomes more diversified, its incentive for investing in basic research relative to applied research should increase due to better appropriability of potential knowledge spillovers. Similarly, we identify the within-industry spillovers of basic and applied research through their impact on subsequent innovations. We show that patents derived from basic research efforts are associated with higher quality of follow-up innovations for approximately 8 years. To further inform the model parameters on firm dynamics, we simultaneously target a rich set of firm characteristics related to multi-industry presence, profitability, age, and entry/exit patterns.

Our main result is the quantification of the inefficiencies due to dynamic misallocation in research. We find that $89 \%$ of spillovers from basic research across industries are not internalized and that basic research makes applied innovation $60 \%$ more productive. As a result, there is a dynamic misallocation of research efforts, which reduces welfare by 3.6 percentage points in consumption equivalent terms. One striking feature of the solution to the social planner's problem is that the fraction of resources devoted to research activities is not substantially greater than in the decentralized equilibrium. Indeed, the dominant misallocation here is not that between production and research, as is common in this class of models, but among the various types of research activities, in this case, applied and basic innovation. Another striking feature is that in the case of applied innovation, there is actually an overinvestment in the decentralized economy due to the strategic complementarity between basic research spillovers and the returns to applied research.

This raises an important question: to what extent can public policies address this inefficiency? The first policy we analyze is a uniform research subsidy to private firms. In this environment, subsidizing overall private research is ineffective since this policy oversubsidizes applied research, which is already overinvested in due to competition. Therefore, the welfare improvement from such a subsidy is limited unless the policymaker is able to discriminate between types of research projects at the firm level. We thus consider a hypothetical type-dependent research subsidy and find that the optimal policy is to subsidize basic research by $50 \%$ and applied research by $14 \%$. Finally, we show that increased funding to public basic research labs (e.g., universities) can have significant welfare improvements, especially when the speed of the transmission of their research findings to the private sector is increased.

Related Literature Our main contribution is to the macro literature on endogenous technical change. Although the different characteristics of basic and applied research, and public and private research have been widely recognized to be of first-order importance by policymakers, these issues have received insufficient attention from the economic growth literature. In particular, models of endogenous technological change (see Aghion, Akcigit, and Howitt (2014) for a recent survey) mainly considered a uniform type of (applied) research and ignored basic research investment in the economy. A few exceptions are Aghion and Howitt (1996, 2009), Cozzi and Galli (2009, 2014), Gersbach, Schneider, and Schneller (2013), Gersbach and Schneider (2015), Morales (2004), and Mansfield (1995), who 
have considered theoretical models with both basic and applied research investment. We contribute to this literature by building a model with rich firm dynamics as in Klette and Kortum (2004) and Lentz and Mortensen (2008) that is estimated with new firm-level micro data on firms' research investment. In addition to including the private investment in basic research, we enrich the analysis of the distinct features of basic research by introducing a novel method to identify within- and crossindustry spillovers.

Methodologically, our paper is related to the growing branch of endogenous growth with firm dynamics that estimates these models structurally using micro data. For instance, Lentz and Mortensen (2008, 2016) use a panel of Danish firms, Acemoglu, Akcigit, Bloom, and Kerr (2013), Akcigit and Kerr (2016), and Garcia-Macia, Hsieh, and Klenow (2015) use US Census of Manufacturing and Peters (2015) uses Indonesian micro data, and Ates and Saffie (2014) use Chilean firm-level data to estimate enriched versions of the quality-ladder models. A number of papers have also studied the role of innovation policy in similar class of models. For instance, Atkeson and Burstein (2015) study the impact of policy-induced changes in innovative investment by firms on growth in aggregate productivity. More recently, Akcigit, Hanley, and Stantcheva (2016) use a mechanism design approach to solve for the optimal design of innovation policy using a quality-ladder model with asymmetric information on firm types. Finally, Garicano, Lelarge, and Van Reenen (2016) have used firm-level data to study the impact of size-dependent policies on misallocation of factors of production in France. These papers do not consider the distinction between basic and applied research, whereas our focus here is to estimate the associated spillovers using French firm-level data and design relevant policies around these spillovers.

Consistent with our results, some papers show that the speed of technology diffusion is linked to the ability of inventors to utilize ideas for production (Akcigit, Celik, and Greenwood, 2016), or to the existing patent rights over those technologies (Galasso and Schankerman, 2015). In the same spirit, Bloom, Schankerman, and Van Reenen (2013) identify technology and product market spillovers for US manufacturing firms. They show that small firms generate lower social returns to R\&D because they operate in technological niches. Our paper, suggests that their result can be rationalized by these firms' lower incentives to invest into basic research which is more difficult to appropriate. In our framework, more public basic research investment stimulates more private applied research. In that regard, our results are parallel with the findings of Cozzi and Impullitti (2010) and Impullitti (2010) which show that increases in the technological content of public spending encourages more private R\&D spending in the US.

The rest of the paper is organized as follows. The discussion of our theoretical framework consists of two parts: In Section 2 we provide a benchmark version of the main model, characterize its dynamic equilibrium in an intuitive manner, and discuss the main mechanisms. We then describe a generalization of the benchmark model that we bring to the data and estimate. Section 3 describes the estimation and identification of the model. Section 4 provides a detailed discussion of the welfare effects of various policies on the decentralized economy. Section 6 concludes. The Appendix contains omitted proofs and derivations (A), the data description (B), further details on within-industry 
spillovers (C), robustness checks on the stylized facts (D), and further details on identification (E).

\section{Theory: Growth with Basic and Applied Research}

Our theoretical framework will depart from standard endogenous growth models in a number of ways. First, we introduce a distinction in the appropriability of innovations from basic and applied research. Following the influential literature on basic science, we consider the possibility that basic research not only generates spillovers within an industry, but also across industries (Nelson, 1959). We thus model an economy in which firms can operate in multiple industries, a feature that endogenously generates incentives for firms to invest into basic research.

A second key feature of our model is the distinction between embodied and disembodied knowledge in the economy. Both private firms and public research labs are investing into basic research in this economy. However successful basic research in the the private sector is more likely to be immediately turned into a consumer product (embodied), as opposed to simply increase the stock of knowledge available for future innovators (disembodied). This will induce a delay in the effect of public basic research. The ivory tower nature of academic research has been widely discussed in academic and policy circles, with a formal analysis being provided by Aghion, Dewatripont, and Stein (2008). ${ }^{1}$

For ease of exposition and intuition, in this section, we will first outline a simplified baseline framework with myopic (one-period-ahead maximizing) firms that highlights the key elements of the main model. After deriving the theoretical results and discussing the main economic forces at play, in Section 2.3 we will describe the generalizations we make to the benchmark model.

\subsection{Baseline Model}

We consider a representative household economy in continuous time. The household consists of a measure $M$ of workers. Each worker has one unit of labor that is supplied inelastically in the labor market. There is a unique final good $Z(t)$. The economy is a closed economy, there is no physical capital investment and all expenses are in terms of the labor units. Therefore, $Z(t)$ will also be equal to household consumption at time $t$.

\subsubsection{Production}

Production is divided into three major sectors: downstream, midstream, and upstream. The upstream sector produces intermediate goods $\left(y_{i j}\right)$ that are used to produce industry aggregates $\left(Y_{i}\right)$ in the midstream sector. Finally, the downstream sector combines these industry aggregates into the final good $(Z)$. We will now describe them in detail.

\footnotetext{
${ }^{1}$ In their model the academic sector is a precommitment mechanism that allows scientists to freely pursue their own interests. Consistent with our model, academic scientists may therefore end up working on projects with little immediate economic value. An important difference however is that in their setup there is full appropriability of the innovation. We relax this assumption and show that it generates a delay in the innovation process with consequences for economic growth.
} 
Downstream Sector The final good $Z(t)$ is produced in the downstream sector by infinitely many competitive firms that combine inputs from $M$ different industries according to the following constant elasticity of substitution (CES) production function

$$
Z(t)=\left[\frac{1}{M} \sum_{i=1}^{M} Y_{i}(t)^{\frac{\gamma-1}{\gamma}}\right]^{\frac{\gamma}{\gamma-1}}
$$

In this production function, $Y_{i}(t)$ is the aggregate output from industry $i \in\{1, \ldots, M\}$. The economy consists of $M \in \mathbb{Z}_{+}$industries. In the context of firm-level data, each industry $i$ can be thought of as a different 1-digit Standard Industrial Classification (SIC) code and $Z(t)$ is simply the aggregate GDP of the economy. ${ }^{2}$ We normalize the price of the final good to 1 at every instant $t$ without any loss of generality. For notational simplicity, time subscripts will henceforth be suppressed.

Midstream Sector Each industry aggregate $Y_{i}$ is produced competitively, combining inputs from a continuum of product lines. Let $y_{i j}$ denote the production of upstream good $j$ in industry $i$ by the firm that has the best technology in that product line. Industry aggregate $i$ is produced according to the following CES production function

$$
Y_{i}=\left[\int_{0}^{1} y_{i j^{\frac{\varepsilon-1}{\varepsilon}}}^{\varepsilon^{\frac{\varepsilon}{\varepsilon-1}}}\right.
$$

Upstream Sector In product line $j$, the firm that has the latest (and also the best) technology produces as a monopolist according to the following linear production technology that takes only labor as an input

$$
y_{i j}=q_{i j} l_{i j}
$$

where $q_{i j}>0$ is the labor productivity associated with product line $j$ and $l_{i j}$ is the number of production workers employed. Let us denote the wage rate in the economy by $w$ in terms of the final good. The specification in (3) implies that each product $y_{i j}$ has a constant marginal cost of production $w / q_{i j}>0$. We denote the productivity index of industry $i$ by

$$
\bar{q}_{i} \equiv\left(\int_{0}^{1} q_{i j}^{\varepsilon-1} d j\right)^{\frac{1}{\varepsilon-1}} .
$$

Definition of a Firm In this model, as in Klette and Kortum (2004), a firm is defined as a collection of product lines in which it is the lead producer. These product lines can come from multiple industries. In what follows, $m_{f} \in\{1, \ldots, M\}$ will denote the number of industries in which the firm actively operates, $n_{i f} \in \mathbb{Z}_{+}$will denote the number of product lines firm $f$ owns in a given industry $i$, and finally $n_{f}$ will stand for the total number of product lines owned by the firm and will satisfy $n_{f} \equiv \sum_{i \in m} n_{i f}$. For notational tractability, henceforth we will drop the firm index $f$, when it creates no confusion.

\footnotetext{
${ }^{2}$ Note that we introduce this multi-industry structure in order to model cross-industry spillovers. To avoid any additional theoretical complications, we will focus on symmetric equilibria in which industry aggregates assume a common value.
} 
A firm's payoff in a given product line $j$ in industry $i$ depends on its productivity level $q_{i j}$. Therefore, the payoff-relevant state of a firm is denoted by

$$
\mathbf{q}=\left(\mathbf{q}_{1}, \mathbf{q}_{2}, \ldots, \mathbf{q}_{m}\right)
$$

where $\mathbf{q}_{i}=\left\{q_{i, 1}, q_{i, 2}, \ldots, q_{i, n_{i}}\right\}$ is a multi-set keeping track of all the productivity levels of the firm in industry $i$ where it has the best technology. ${ }^{3}$ Working with such a large and complex state space proves burdensome in practice. Later on, we will impose sufficient assumptions that allow us to use a much simpler equivalent representation of a firm's product portfolio.

Example 1 An example is helpful to summarize the description so far. Figure 3 illustrates an example of an economy that consists of $M=3$ industries. It also shows an example of a firm $(f)$ that operates in $m=2$ industries $\left(i=1\right.$ and $i=3$ ) and has $n_{1}=3$ product lines in industry $i=1$ and $n_{3}=2$ product lines in $i=3$. This firm does not currently operate in industry $i=2$.

FigURE 3: EXAMPLE OF A FIRM

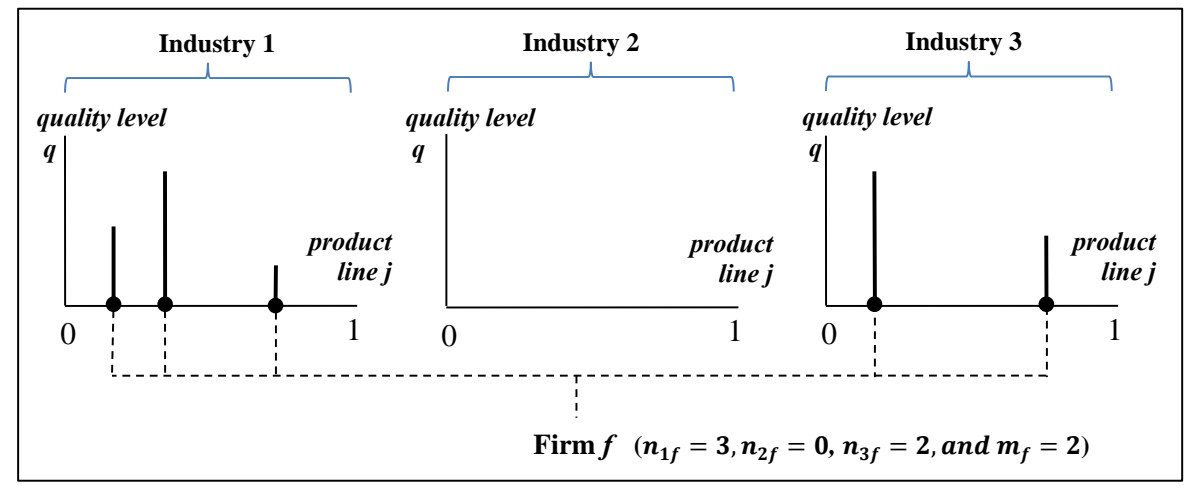

A firm's portfolio of products will expand through successful innovation. Likewise, it will lose product lines when other firms or potential entrants successfully innovate on one of its product lines (thus stealing it). These innovations will be the source of economic growth in this economy. The next subsection will describe the details of the innovation technology.

\subsubsection{Innovation and Technological Progress}

In this economy, there are two types of innovations (basic and applied) and two different groups of agents (private and public sectors) generating productivity growth.

Firms invest in both basic and applied research, thus generating innovations that drive productivity growth. As Nelson (1959) and Aghion and Howitt (1996) describe it, fundamental advances in technological knowledge come through basic innovation and open up windows of opportunity for future research. Applied innovation builds on these existing basic innovations, thus realizing these opportunities. That being said, innovations eventually run into diminishing returns. If the latest basic innovation in a product line becomes outdated, applied innovations in that product line become less

\footnotetext{
${ }^{3} \mathrm{~A}$ multi-set is a generalization of a set that can contain more than one instances of the same member. For instance, given $j \neq j^{\prime}$, a multiset $\mathbf{q}_{i f}$ can contain $q_{i f}(j)$ and $q_{i f}\left(j^{\prime}\right)$ regardless of whether $q_{i f}(j)=q_{i f}\left(j^{\prime}\right)$.
} 
productive until a new basic innovation introduces additional fundamental knowledge that can make the applied innovation more productive again. Therefore, there will be complementarity between the two types of innovation at the aggregate level.

These innovations come from two sources: First, the private sector invests in both basic and applied innovation with the goal of increasing their market share. Second, the government uses tax revenues to fund public research labs to produce basic innovations. In what follows, we are going to describe firms' research technology and the distinction between basic and applied research. Then we will describe the public research technology.

Research by Private Firms Firms choose their flow rate of innovation and pay a labor cost that is increasing and convex in this rate. Basic and applied research levels are chosen separately, and there is no complementarity between them in terms of research costs. For the innovation production function, we will follow the literature (see Klette and Kortum (2004), Lentz and Mortensen (2008), Acemoglu, Akcigit, Hanley, and Kerr (2016), and Acemoglu, Akcigit, Bloom, and Kerr (2013)). Firms undertake innovation by combining their existing, non-tradable intangible capital with researchers (hired at wage rate $w$, as with production workers) in a Cobb-Douglas production function. In our model, the intangible capital stock in a particular industry $i$ is proxied by the number of product lines $n_{i}$ that a firm owns in that industry. The production function for applied and basic research then takes the following form

$$
A_{i}=n_{i}^{1-\frac{1}{\nu_{a}}} H_{a i}^{\frac{1}{\nu_{a}}} \Omega_{a} \quad \text { and } \quad B_{i}=n_{i}^{1-\frac{1}{\nu_{b}}} H_{b i}^{\frac{1}{\nu_{b}}} \Omega_{b}
$$

where $\Omega_{a}, \Omega_{b}>0$ are scale parameters, $\nu_{a}, \nu_{b}>1$ are the inverse of the innovation production function elasticities with respect to researchers and $H_{a i}$ and $H_{b i}$ denote the number of researchers that firm $f$ needs to hire in order to generate the Poisson flow rates for applied $\left(A_{i}\right)$ and basic research $\left(B_{i}\right)$ in industry $i$.

The above specifications, which are standard in this class of models, capture the idea that a firm's knowledge capital facilitates innovation. ${ }^{4}$ Let us define $a_{i} \equiv A_{i} / n_{i}$ and $b_{i} \equiv B_{i} / n_{i}$ as the applied and basic innovation intensities. Similarly, let $h_{a}\left(a_{i}\right) \equiv H_{a i} / n_{i}$ and $h_{b}\left(b_{i}\right) \equiv H_{b i} / n_{i}$ be defined as the number of researchers per product line hired for applied and basic research. As a result, we can summarize the cost of doing applied and basic research as

$$
C_{a}\left(a_{i} \mid n_{i}\right)=w n_{i} a_{i}^{\nu_{a}} \xi_{a} \quad \text { and } \quad C_{b}\left(b_{i} \mid n_{i}\right)=w n_{i} b_{i}^{\nu_{b}} \xi_{b}
$$

where $w$ is the wage rate, $\xi_{a} \equiv \Omega_{a}^{-\nu_{a}}$, and $\xi_{b} \equiv \Omega_{b}^{-\nu_{b}}$. Notice that total cost is directly proportional to the number of product lines.

Similar to Klette and Kortum (2004), Lentz and Mortensen (2008), Acemoglu, Akcigit, Hanley, and Kerr (2016), and Acemoglu, Akcigit, Bloom, and Kerr (2013), both applied and basic research are directed toward particular industries but undirected within those industries. In other words, once

\footnotetext{
${ }^{4}$ It also simplifies the analysis by making the problem proportional to the number of product lines.
} 
a firm chooses $A_{i}$ and $B_{i}$, the realization of innovations will take place on a random product within industry $i$.

Innovation through basic research introduces a new generation of fundamental technical knowledge. The utilization of this fundamental knowledge for production requires that the firm have what we call industry-specific working knowledge. This translates one of the main insights on basic research presented in the introduction into our model. Although the knowledge generated by basic research is often applicable to many industries, the ability to turn it into patents and capture its full economic value critically depends on the spectrum of activities and technologies operated by the firm. In the model, we say that each firm has sufficient working knowledge for utilization only in the industries where it has undertaken production $(m)$. For now, we take the joint distribution $\Gamma_{m, n}$ over $m$ and $n$ as given but we will endogenize it in the generalized model in Section 2.3.

Let $q_{i j}(t)$ be the highest productivity technology for producing $j$ in industry $i$. When a firm that has working knowledge in $i$ produces a basic innovation that has a direct application in industry $i$ and product line $j$, the same firm uses this basic knowledge for production and patents this new high-value technology. As a result, the firm improves $q_{i j}(t)$ by $\eta \bar{q}_{i}(t)$

$$
q_{i j}(t+\Delta t)=q_{i j}(t)+\eta \bar{q}_{i}(t)
$$

where $\eta>0$ is the step size, and $\bar{q}_{i}$ is the productivity index defined in equation (4). When the firm produces this new innovation, it adds this product line with the productivity improvement into its portfolio $\mathbf{q}(t+\Delta t)=\mathbf{q}(t) \cup\left\{q_{i j}(t+\Delta t)\right\}$, which generates per-period profit of $\pi\left(q_{i j}(t+\Delta t)\right)$. Going back to Example 1, firm $f$ would increase its total number of product lines from 5 to 6 with this basic innovation.

Moreover, basic research features two potential spillovers:

- within-industry spillover: Each new basic innovation changes the evolution of the product line by introducing a radically new technology. The introduction of this new basic technology causes subsequent applied innovations to be larger until the latest basic technology becomes outdated through some random process. We refer to product lines just hit by basic innovation as hot product lines, as opposed to cold product lines, whose latest basic innovation has become outdated.

- cross-industry spillover: Each new basic innovation has the potential for spillovers into other industries. With some probability a basic innovation will generate an additional basic innovation in some other industry. If the firm has working knowledge in this other industry, it can use the innovation for production. Otherwise, the new technology contributes to the pool of existing basic knowledge and will eventually contribute to a new consumer product made by some other producer.

These two types of spillovers lie at the heart of our analysis; therefore, we will now discuss each in more detail. 
Within-Industry Spillover from Basic Research Applied research makes use of the withinindustry spillover from basic research and builds on the existing latest basic technological knowledge in a product line. The productivity of each applied innovation is a function of how depreciated the latest basic technology is. If the latest basic knowledge in $j$ is undepreciated (i.e., still hot), a successful applied innovation will benefit from it and improve the latest productivity $q_{i j}(t)$ of that product line by $\eta \bar{q}_{i}(t)$, as in expression $(6): q_{i j}(t+\Delta t)=q_{i j}(t)+\eta \bar{q}_{i}(t)$. If the latest basic technology of the product line is depreciated (i.e., cold), a successful applied innovation will improve the latest productivity only by an amount proportional to $\lambda<\eta$ so that

$$
q_{i j}(t+\Delta t)=q_{i j}(t)+\lambda \bar{q}_{i}(t)
$$

We assume that a new basic technology depreciates (innovations run into diminishing returns) at a Poisson rate $\zeta>0$. On the other hand, a new basic innovation reactivates the product line until the next time it cools down again. Let us denote the arrival rate of basic innovations to product lines by $\tau_{b}$. Then during a small time interval $\Delta t$, each product line will be subject to the transition rates denoted in Table 1:

TABle 1: TRANSITION MATRIX FOR WITHIN-INDUSTRY SPILLOVERS

\begin{tabular}{c|c|c|}
\multicolumn{1}{c}{ hot } & \multicolumn{1}{c}{ cold } \\
\cline { 2 - 3 } hot & $1-\zeta \Delta t$ & $\zeta \Delta t$ \\
\cline { 2 - 3 } cold & $\tau_{b} \Delta t$ & $1-\tau_{b} \Delta t$ \\
\cline { 2 - 3 } & &
\end{tabular}

$\begin{array}{lll}\text { Industry } 1 & \text { Industry } 2 & \text { Industry } 3\end{array}$

Figure 4 illustrates the implications of within-industry spillovers. In every industry, at any point quality level $\quad$ quality level

in time, some proquct lines will be $\operatorname{hot}_{\boldsymbol{q}}$ (red dotted lines) and $\boldsymbol{q}$ some product lines will be cold, in cases where the latest technology is outdated (black solid lines). We will denote the share of hot

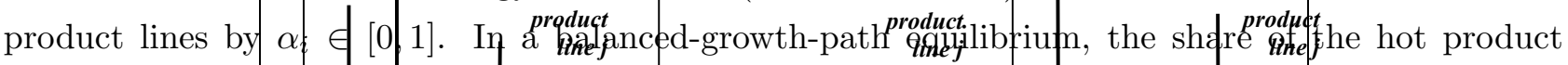
lines will be determined through the transifion rates in Table 1 and will remain invariant. An applied innovation is more productive-if the-latest-basic rkmowledge-im-that-product-line is still "hot" and

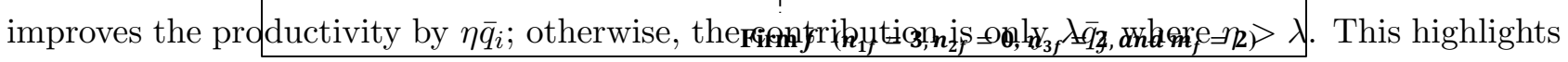
the complementarity between basic and applied research.

\section{FIgURE 4: WITHIN-INDUSTRY SPILLOVER}
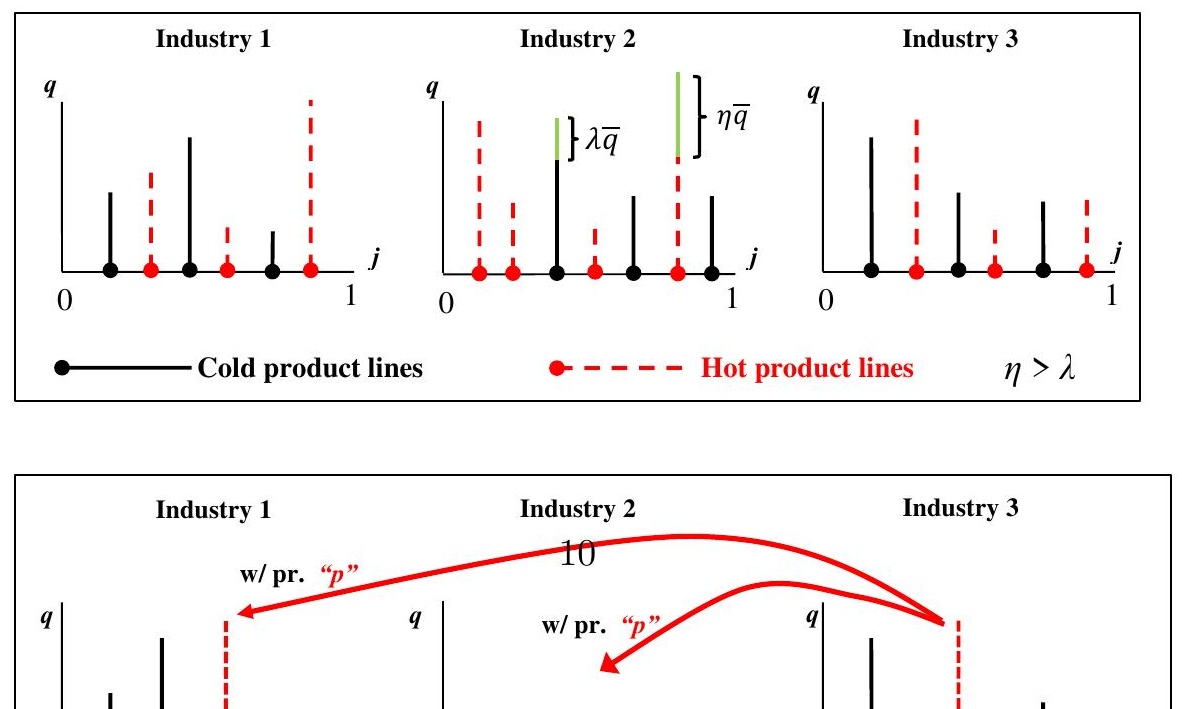
Cross-Industry Spillover from Basic Research Basic research features an additional element of uncertainty arising from random spillovers into other industries. When a firm successfully innovates through basic research, the resulting new fundamental knowledge will be applied first by that firm to increment the productivity of a random product in the target industry.

The characteristic feature of basic research we wish to capture is that it often has applications in many industries other than the one for which it was originally intended. Therefore, we will assume that when a basic innovation occurs, it applies with probability one to the target industry, and with probability $p \in(0,1)$, it generates an additional basic innovation in another industry determined by nature at random. Thus, $p$ is our measure of the intensity of cross-industry spillovers. Let $\mathbf{1}_{i, i^{\prime}}$ be an indicator function that takes a value of one if a basic innovation in industry $i$ has an application in industry $i^{\prime}$ and zero otherwise. Then the unconditional probabilities satisfy

$$
\operatorname{Pr}\left[\mathbf{1}_{i, i^{\prime}}=1\right]=\left\{\begin{array}{cl}
\frac{p}{M-1} & \text { if } i^{\prime} \neq i \\
1 & \text { if } i^{\prime}=i
\end{array} .\right.
$$

The spillover innovation in industry $i^{\prime}$ will be of step size $\eta$ as well but will not generate additional crossindustry spillovers. This new innovation will be used by the same firm $f$ if it has working knowledge in $i^{\prime}$. Otherwise the production potential of this innovation will be used by the next inventor in that product line.

This structure captures a hypothesis put forth by Nelson (1959). When a firm generates some basic knowledge, it can turn this into an immediate application only in the sectors in which it has working knowledge. In order to capture the full return from new basic scientific knowledge in industries where a firm is not present but the knowledge could have an application, the innovating firm must first patent and then license or sell the innovation to other firms in those industries. However, the applications of significant scientific advances are often not immediate and firms can generally turn them into patentable applications only in their own industries using their expertise in the field.

Example 2 Cross-industry spillovers are depicted in Figure 5. Firm $f$ from Example 1 now produces a basic innovation in industry 3. This adds a new product line to the firm's portfolio and hence the number of product lines of the firm goes from 2 to 3 in $i=3$. In addition, this basic knowledge has a potential application in industries $i=1$ and $i=2$ with probability $p$. The spillover in industry $i=1$ is used by the firm since it has working knowledge there. However, the application in $i=2$ is not immediate to the firm due to lack of working knowledge and therefore it is not used by the current firm but contributes to the pool of basic knowledge in $i=2$, which can be used by another firm in the future.

Recall that $m$ denotes the number of industries in which a firm has working knowledge. Then the probability of a utilized spillover for the firm is

$$
\rho_{m} \equiv \frac{p(m-1)}{M-1} \in[0,1) .
$$

This highlights the well-known appropriability problem of basic research. There is a significant chance that the new basic knowledge will be relevant to multiple industries, but it is not always clear that a 


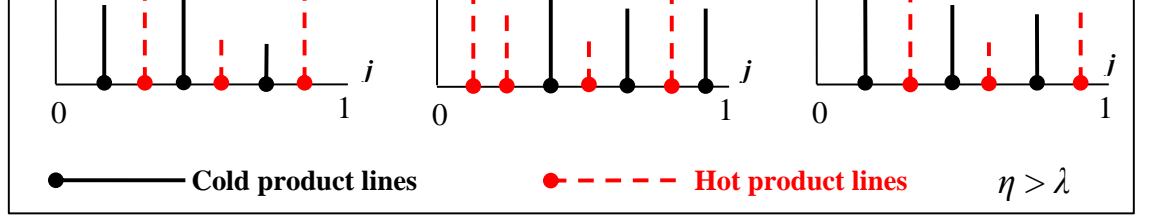

Figure 5: Cross-Industry SPILlover

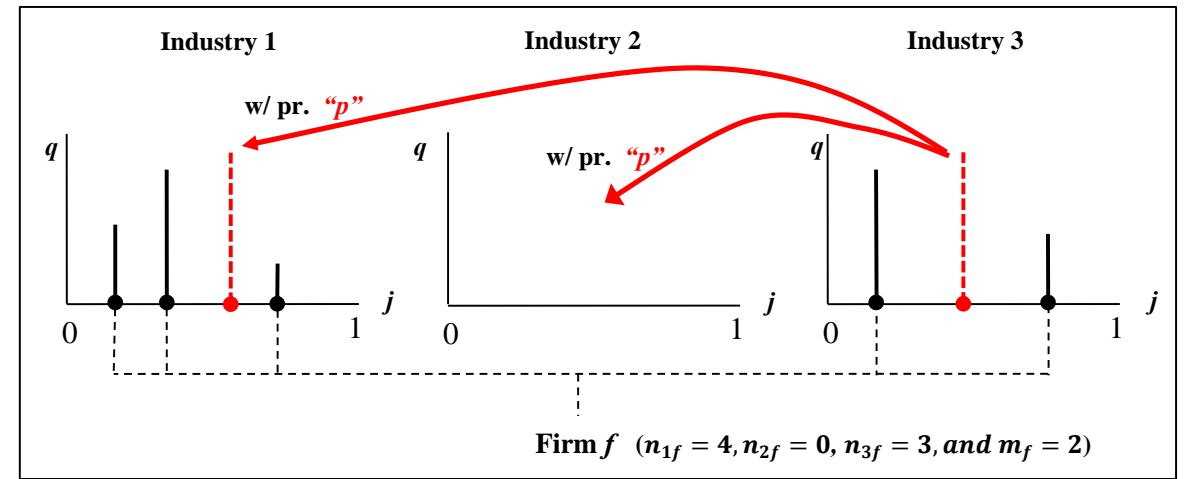

firm will be in a position to exploit all of these avenues of production and patenting. However, firms operating in more industries will have a greater probability of being able to directly use all facets of a basic innovation. As Nelson puts it, firms that have fingers in many pies have a higher probability of using the results of basic research. A broad technological base increases the probability of benefiting from successful basic research.

Public Basic Research In our model, the academic sector will be the other source of basic knowledge creation. One of the main tasks of public research labs in an economy is to produce the necessary basic scientific knowledge that will be part of the engine for subsequent applied innovations and growth. We assume that the public research sector consists of a measure $U$ of research labs per industry. Each lab receives the same transfer $\bar{R}$ from the government to finance its research which results in an overall funding level of $R=\bar{R} \times U \times M$.

We assume that each public research lab generates a flow rate of $u$ by hiring $h_{u}$ researchers with the same basic research technology as a one-product firm in (5), so that $u=\Omega_{b} h_{u}^{\frac{1}{\nu_{b}}}{ }^{5}$ This specification implies that the government can affect the basic knowledge pool in the economy through the amount of funds $R$ allocated to the academic sector. The flow rate of basic innovation from the academic sector will satisfy

$$
u=(\bar{R} / w)^{\frac{1}{\nu_{B}}} \Omega_{b}
$$

where $u$ is the academic basic innovation flow per lab. In this economy, $R$ is a policy lever controlled by the policymaker. As with private firms, each basic innovation generated by the academic sector applies to industry $i$ and a random product line $j$ and makes that product line hot. However, this innovation by public labs will turn into output only upon a subsequent private applied innovation. In addition to $i$, the same basic knowledge will contribute to the basic knowledge pool in another industry $i^{\prime} \neq i$ and line $j^{\prime}$ with probability $p \in(0,1)$. Note that the equilibrium fraction of hot product lines $\alpha$ will be determined by the aggregate rates of public $(u)$ and private $\left(b_{m}\right)$ basic research as well as the cool-down rate $(\zeta)$.

\footnotetext{
${ }^{5}$ In reality, public research labs may have a different research technology than private labs. However, obtaining data on both the inputs and outputs of individual public labs is difficult. The separate estimation of public and private innovation production functions is left for future research.
} 
Remark It is important to note that we assume that innovation done by public labs is turned into consumer products only upon subsequent innovation by private firms. The lag between the creation of publicly funded innovations and actual goods production is empirically shown in a large literature. ${ }^{6}$ This important issue is generally overlooked in the theoretical growth literature. Inclusion of this feature generates some new and interesting dynamics, such as the importance of involvement of the private sector in basic research.

Entry and Exit The research technology for a single outside entrant is assumed to be the same as that of applied innovation for a firm with a single product line. Thus if an outside entrant hires $h_{e}$ researchers, it produces a flow probability of entry of $a_{e}=h_{e}^{\frac{1}{\nu_{a}}} \Omega_{a}$.

There is a mass $E$ of outside entrants per industry. Varying this parameter will control the relative importance of outside entry in the economy. This will imply that creative destruction arising from new entrants will be equal to $E \times a_{e}$.

In our model, there will be both endogenous and exogenous channels for firm exit. First, a firm that loses all of its product lines to other competitors will have a value of zero and thus will exit. Second, each firm has an exogenous death rate $\kappa>0$. When this occurs, the firm sells all of its product lines to random firms at a "fire sale" price $\mathcal{P} .{ }^{7}$ On the flip side, firms will receive a buyout option with a probability that is proportional to their number of products.

Labor Market Labor is split between production $\left(L_{p}\right)$ and research labor. Research labor can be further subdivided into that devoted to private basic $\left(L_{b}\right)$, public basic $\left(L_{u}\right)$, private applied research $\left(L_{a}\right)$ and firm entry $\left(L_{e}\right)$. Since the total labor supply is $M$ workers, the labor market clearing condition is given by

$$
M=L_{p}+L_{b}+L_{a}+L_{e}+L_{u}
$$

The labor utilization from each component can be expressed in a more concise form when we investigate the properties of the dynamic equilibrium in the next section.

Household Problem Finally, we close the model by describing the household problem that determines the equilibrium interest rate in this model. The household consumes the final good and maximizes the following lifetime utility

$$
W_{0}=\int_{0}^{\infty} \exp (-\delta t) \frac{C(t)^{1-\gamma}-1}{1-\gamma} d t
$$

where $C(t)$ is consumption at time $t, \gamma$ is the constant relative risk aversion parameter, and $\delta$ is the discount rate. The household owns all the firms in the economy, which generates a risk-free flow return of $r$ in aggregate. The household also supplies labor in the economy, through which it earns wage rate $w(t)$. Finally, the household pays a lump-sum tax $T(t) \geq 0$ every instant. Thus, the household's

\footnotetext{
${ }^{6}$ Rosenberg and Nelson (1994), and Mowery, Nelson, Sampat, and Ziedonis (2004), among several others.

${ }^{7}$ The exact value of this price will not play any role for the equilibrium determination.
} 
intertemporal maximization is simply to maximize (10) subject to the following budget constraint

$$
C(t)+\dot{A}(t) \leq r(t) A(t)+M w(t)-T(t)
$$

where $A(t)$ is the asset holdings of the household.

\subsection{Equilibrium}

In this section, we characterize the dynamic equilibrium of our model. Our focus is on a symmetric balanced-growth-path (SBGP) equilibrium where all industries start with the same initial conditions at time $t=0$ and all aggregate variables grow at the same endogenous rate $g$.

In this model, three variables affect the payoff of the firm: the number of product lines $n$, the number of industries $m$, and the relative productivity

$$
\hat{q}_{i j} \equiv q_{i j} / \bar{q}_{i}
$$

of its product lines, which is the absolute productivity in line $j$ normalized by the productivity index $\bar{q}_{i}$ in industry $i$. Thus, each incumbent firm is characterized by its state $k \equiv(\hat{\mathbf{q}}, n, m)$.

More specifically, given a government policy sequence $[T(t)]_{t=0}^{\infty}$, an SBGP equilibrium is composed of a sequence of intermediate good quantities, prices, the basic and applied innovation rates of private firms and entrants, the wage rate and interest rate, the joint distribution of multi-industry presence and product count, hot and cold product line productivity distributions, the fraction of hot product lines, i.e., $\left[y_{k}(t), p_{k}(t), b_{k}(t), a_{k}(t), a_{e}(t), w(t), r(t), \Gamma_{m, n}(t), \mathcal{F}_{H}(t), \mathcal{F}_{L}(t), \alpha(t)\right]_{t=0}^{\infty}$, such that all firms choose quantity and price to maximize their profits, incumbent and entrant firms invest in research to maximize their firm value, the labor market clears, the household maximizes its discounted sum of future utilities, and the distributions satisfy the relevant flow equations.

Solution of the Model The standard monopoly profit maximization delivers the following familiar equilibrium price and quantities (interested readers are referred to the Appendix Section A for the detailed derivations)

$$
y_{j}=\hat{q}_{j}^{\epsilon} Z \quad \text { and } \quad p_{j}=\frac{1}{M \hat{q}_{j}} .
$$

Clearly, a monopolist's quantity is increasing and price decreasing in the relative productivity $\hat{q}$ of the product line. Finally, the equilibrium profits of the monopolist are again increasing in its relative productivity $\hat{q}$ and the average market size $Z / M$ :

$$
\pi(\hat{q})=\frac{\hat{q}^{\varepsilon-1}}{\varepsilon} \frac{Z}{M} .
$$

Next, only in this section, we focus on myopic firms that maximize their one-period-ahead returns (as opposed to forward-looking firms that maximize the discounted sum of future profits). This will allow us to provide some useful analytical results and highlight the key economic forces of our model. In our quantitative analysis (Section 3), we will generalize this and focus on forward-looking firms. 
Myopic Firms Consider now a firm that has $n$ product lines in $m$ industries. Moreover, in an SBGP, an $\alpha$ fraction of product lines are hot. Then the maximization problem when deciding for the amount of basic research can be written as

$$
\max _{b_{m}}\left\{n b_{m}\left(1+\rho_{m}\right) V^{H}-\tilde{w} n b^{\nu_{b}} \xi_{b}\right\}
$$

where $V^{H} \equiv \mathbb{E}_{\hat{q}}^{H} \pi(\hat{q}+\eta)$ is the expected return to a successful basic innovation and $\tilde{w} \equiv \frac{w}{Z / M}$ is the normalized wage rate. Several observations are in order. First, the expected return from basic research investment is increasing as the firm has fingers in more pies as Nelson argued (higher $\rho_{m}$ ). Second, the innovations are undirected within industries; therefore, the firm has to form an expectation for the expected profit $\mathbb{E}_{\hat{q}}^{H} \pi(\hat{q}+\eta)$, which means that we have to keep track of the invariant relative productivity distribution to compute $V^{H}$. Finally, both the returns and the costs are proportional to the number of product lines $n$, which makes the problem much more tractable and the quantitative solution manageable. Now we can express the first-order condition as

$$
b_{m}=\left[\frac{\left(1+\rho_{m}\right) V^{H}}{\nu_{b} \xi_{b} \tilde{w}}\right]^{\frac{1}{\nu_{b}-1}}
$$

The most important result here is the fact that basic research investment is increasing in the multiindustry presence of the firm. The strength of this positive relationship will be mainly governed by the probability of the cross-industry spillover parameter $p$, which will help us match Figure 2.

Fact 1 A firm's basic research investment is increasing in its multi-industry presence.

Both private firms and public research labs are generating basic research in this economy. It is useful to break down total basic research into its embodied and disembodied components. The distinction is based on whether the basic knowledge is immediately turned into a consumer product (embodied) or simply added to the stock of knowledge available for future innovators (disembodied). We obtain the following aggregates

$$
\begin{aligned}
\text { Embodied: } \tau_{b}^{e} & \equiv \sum_{m=1}^{M} \mu_{m}\left(1+\rho_{m}\right) b_{m} \\
\text { Disembodied: } \quad \tau_{b}^{d} & \equiv \sum_{m=1}^{M} \mu_{m}\left(p-\rho_{m}\right) b_{m}+(1+p) u \\
\text { Total: } \quad \tau_{b} & \equiv \tau_{b}^{e}+\tau_{b}^{d}
\end{aligned}
$$

where we define the mass of product lines owned by firms in $m$ industries by $\mu_{m}$, which can be computed from the joint distribution using $\mu_{m} \equiv \sum_{n=1}^{\infty} n \cdot \Gamma_{m, n}$. Then $\tau_{b}^{e}$ and $\tau_{b}^{d}$ correspond respectively to the embodied and disembodied components of basic research. Note that the disembodied component includes both private spillovers that are unused and the results of public basic innovation. Finally, $\tau_{b}$ is simply the overall flow of basic innovation, including all spillovers.

Using this aggregate rate and the cool-down rate $\zeta$, we can express the steady-state flow equation: the number of product lines that become hot must be equal to the number of product lines that cool 
down. In other words, we must have $\alpha \zeta=(1-\alpha) \tau_{b}$. As a result, the steady-state fraction of hot product lines is

$$
\alpha=\frac{\tau_{b}}{\zeta+\tau_{b}} .
$$

The share of hot product lines, those having basic knowledge that can be turned into better consumer products $(\alpha)$, is increasing in the amount of basic research flow. This expression highlights the role of public policy in affecting the knowledge stock. The more money is allocated to public basic research, the higher will be the basic research flow from public research labs $(u)$, which will then increase the fraction of hot product lines through $\tau_{b}$, as in (14) and (15).

However, a bigger $\alpha$ is meaningful only when there is subsequent applied research that turns this existing basic knowledge stock into consumer products. Therefore, we now turn to the applied research decision of the firms. Their maximization problem is simply

$$
\max _{a}\left\{n a\left[\alpha V^{H}+(1-\alpha) V^{C}\right]-\tilde{w} n a^{\nu_{a}} \xi_{a}\right\}
$$

where $V^{H} \equiv \mathbb{E}_{\hat{q}}^{H} \pi(\hat{q}+\eta)$ is the expected returns from hot product lines and $V^{C} \equiv \mathbb{E}_{\hat{q}}^{C} \pi(\hat{q}+\lambda)$ is that from cold ones and $\tilde{w}=\frac{w}{Z / M}$ is the normalized wage rate. When investing in applied research, firms form two types of expectations. The first one is due to the undirected nature of research: firms have to form expectations over the relative productivity $\hat{q}$ that they are going to land on. The second, and more important one, is due to the complementarity between basic and applied research: firms take into account the fraction of hot product lines. Firms invest in applied research according to

$$
a=\left[\frac{\alpha V^{H}+(1-\alpha) V^{C}}{\nu_{a} \xi_{a} \tilde{w}}\right]^{\frac{1}{\nu_{a}-1}} .
$$

The crucial observation here is the complementarity between basic and applied research. In equilibrium $V^{H}>V^{C}$ since hot product lines are associated with a larger step size $\eta$. Hence, if there are more hot product lines (a higher $\alpha$ ), each firm increases its investment in applied research.

Fact 2 Basic and applied research investments are complementary. In particular, higher public basic research investment encourages firms to invest more in applied research.

However, the fraction of hot product lines $\alpha$ is not sufficient to determine the incentives for applied research alone due to the correlation between this product state and productivity. The incentives will be a function of the fraction of hot and cold product lines and the average qualities within those types. In particular, firms must know the values of $\mathbb{E}_{\hat{q}}^{H}(\hat{q}+\eta)^{\varepsilon-1}$ and $\mathbb{E}_{\hat{q}}^{C}(\hat{q}+\lambda)^{\varepsilon-1}$ due to the exact form of the profit function in equation (13). Therefore, Lemma 1 describes the laws of motion for the type-specific productivity distributions.

Let us denote the aggregate rate of applied innovation by $\tau_{a}$ such that

$$
\tau_{a}=\sum_{m=1}^{M} \mu_{m} a_{m}+E a_{e} .
$$

Note that in the baseline model, $a_{m}=a$ for all $m$, but this will not necessarily be the case in the general model in Section 2.3. Recall that $\tau_{b}^{e}$ denotes the arrival rate of embodied basic research, as 
defined in (14). Now we can denote the aggregate rate of creative destruction (the rate at which firms lose product lines to other firms) by $\tau$ :

$$
\tau \equiv \tau_{a}+\tau_{b}^{e}
$$

Creative destruction is determined by the rate at which incumbents produce basic innovations which can be embodied into production immediately $\left(\tau_{b}^{e}\right)$, and by the rate at which incumbents and entrants produce applied innovations $\left(\tau_{a}\right)$. Now we are ready to state the following lemma.

Lemma 1 Let $\mathcal{F}_{H}(\cdot, t)$ and $\mathcal{F}_{C}(\cdot, t)$ be the aggregate product cumulative measures by type (hot or cold). The flow equations for these objects are, respectively,

$$
\begin{aligned}
\dot{\mathcal{F}}_{H}(\hat{q}) & =-\tau\left[\mathcal{F}_{H}(\hat{q})-\mathcal{F}_{H}(\hat{q}-\eta)\right]+\tau_{b}^{e} \mathcal{F}_{C}(\hat{q}-\eta)-\zeta \mathcal{F}_{H}(\hat{q})+\tau_{b}^{d} \mathcal{F}_{C}(\hat{q})+g \hat{q}\left[\partial \mathcal{F}_{H}(\hat{q}) / \partial \hat{q}\right] \\
\dot{\mathcal{F}}_{C}(\hat{q}) & =-\tau_{a}\left[\mathcal{F}_{C}(\hat{q})-\mathcal{F}_{C}(\hat{q}-\lambda)\right]-\tau_{b} \mathcal{F}_{C}(\hat{q})+\zeta \mathcal{F}_{H}(\hat{q})+g \hat{q}\left[\partial \mathcal{F}_{C}(\hat{q}) / \partial \hat{q}\right]
\end{aligned}
$$

Proof. See Appendix A.

The labor market clearing condition can now be expressed in terms of the above endogenous variables. One additional relationship we will exploit is that between the mass of labor devoted to production and the normalized wage rate. This can be derived from the goods production specification (see Section A in the Appendix for its detailed derivation)

$$
L_{p}=\frac{Z}{w}\left(\frac{\varepsilon-1}{\varepsilon}\right)
$$

Using this and the symmetric nature of the equilibrium, we express the labor market clearing condition as an average over industries

$$
1=\frac{1}{\tilde{w}}\left(\frac{\varepsilon-1}{\varepsilon}\right)+\xi_{b}\left(\sum_{m} \mu_{m} b_{m}^{\nu_{b}}+U u^{\nu_{b}}\right)+\xi_{a}\left(a^{\nu_{a}}+E a_{e}^{\nu_{a}}\right)
$$

This expression equates the labor supply per industry (=1 since the total labor supply is $M$ ) to labor demand for production workers; private basic researchers, which is a function of the multi-industry presence of the firms; public basic researchers, which is determined by public policy; incumbent applied researchers; and entrant basic researchers.

Finally, plugging the equilibrium intermediate good quantity (12) into the aggregate production functions (2) and (1), we find that the aggregate output is

$$
Z=\bar{q} L_{p} / M
$$

This expression simply says that the aggregate output is equal to the product of the number of workers employed for production and the aggregate productivity index of the economy. In an SBGP equilibrium, the labor allocated for production is constant. Therefore the growth rate of aggregate output (and also output per worker) will be equal to the growth rate of the productivity index $\bar{q}$. The following proposition provides the exact growth rate of the productivity index. 
Proposition 1 In an $S B G P$, the growth rate of the productivity index is

$$
g=\frac{\tau_{a}\left[\alpha \mathbb{E}_{\hat{q}}^{H}(\hat{q}+\eta)^{\varepsilon-1}+(1-\alpha) \mathbb{E}_{\hat{q}}^{C}(\hat{q}+\lambda)^{\varepsilon-1}-1\right]+\tau_{b}^{e}\left[\mathbb{E}_{\hat{q}}(\hat{q}+\eta)^{\varepsilon-1}-1\right]}{\varepsilon-1}
$$

\section{Proof. See Appendix A}

This growth expression shows that the engines of economic progress include both applied and basic innovation. More important, the basic knowledge stock in the economy, represented by $\alpha$, makes each applied innovation more valuable and contributes more to growth (since $\eta>\lambda$ ). This expression shows how public funding can contribute to growth through its indirect impact on private research.

To sum up, let us briefly discuss the sources of inefficiency and what policy can achieve in this model. First, as in standard quality ladder models, there are intertemporal spillovers within each product line. Second, firms simply enjoy the expected duration of monopoly power due to the competition channel of creative destruction. As a result, the private value of innovation differs from the social value of innovation. It is also worth highlighting that in this model, there could be either over- or underinvestment in R\&D. In addition to the standard channels, our model features additional spillovers due to basic research, both within and across industries. Finally, there are additional static distortions due to monopoly power. However, since we are primarily interested in the dynamic inefficiencies associated with innovation and basic research, we will consider the case of a social planner who is still subject to monopoly distortions on the production side.

All of these inefficiencies will generate room for innovation policy, and our estimated model will govern whether there is over- or underinvestment in the various types of research expenditures in the decentralized equilibrium. It will also provide a framework within which to evaluate the effects of these innovation policies.

\subsection{Generalizations of the Model}

The previous section introduced a simplified version of the main model to highlight the key economic forces in analytical forms. Our ultimate goal in this paper is to bring this general equilibrium framework to the data. Therefore, this section generalizes the baseline model to provide richer and more realistic dynamics (with forward-looking firms and heterogeneous innovation qualities, for instance) for the economy and its agents and to give the model some more flexibility to match the data (e.g., introducing the fixed cost of doing basic research). Those not interested in the technical details can skip directly to the quantitative Section 3.

Stochastic Innovation Step Sizes Stokes (1997) argued that technological breakthroughs do not necessarily derive from basic research. According to the "Pasteur Quadrant" hypothesis, applied research efforts can potentially also lead to important technological changes. Our first generalization takes this possibility into account by introducing stochastic innovation step sizes into the model. We assume, as in Klette and Kortum (2004) and Lentz and Mortensen (2008), that these step sizes are drawn from exponential distributions. For basic research, the mean of the distribution is always $\eta$. 
For applied research, the distribution mean is $\eta$ if the product line is hot and $\lambda$ if it is cold. It is important to note that we do not take any stand on the comparison of the average step sizes $(\eta>\lambda$ or vice versa) and let them be determined by the data.

Fixed Cost of Basic Research In our sample, some firms do not invest in basic research. To capture this fact, we generalize the basic research technology by introducing a fixed cost of doing basic research. At each instant, a firm with $n$ product lines draws a fixed labor cost of doing basic research $n \phi \geq 0$, where $\phi$ is distributed according to the distribution $\mathcal{B}(\cdot)$. Then a firm that operates in $n$ product lines and has a fixed cost of basic research $\phi$ this period has the following cost function $C_{b}\left(b_{m} \mid n, \phi\right)=n c_{b}\left(b_{m} \mid \phi\right)$. This implies that firms will follow a cutoff rule as a function of their multi-industry presence $\phi_{m}^{*}$ such that they will not invest in basic research if $\phi>\phi_{m}^{*}$. Otherwise, in addition to the variable cost, they will also pay the fixed cost.

Industry Expansion (Start-up Buy-outs) In the baseline model, we took the working knowledge of the firms $(m)$ as exogenously given. We now endogenize $m$ by introducing the possibility of buy-out offers for new entrants. The economy features $E \times a_{e}$ flow of entry at any instant. We will assume that a $\varsigma$ fraction of new entrants will meet a randomly selected incumbent firm. Thus, an incumbent will have a flow rate of incoming buy-out offers

$$
x \equiv \varsigma E a_{e} / F .
$$

where $F$ is the equilibrium measure of firms. If $\bar{n}$ denotes the average number of product lines per firm, then $F=1 / \bar{n}$. Clearly this new company will be from a new industry with probability $(1-m / M)$ or from an industry that already exists in the incumbent's portfolio with probability $m / M$. Our goal is to keep the M\&A margin as tractable as possible, and we will achieve this by assuming that the M\&A price that the incumbent firm has to pay is equal to the full surplus of the new merger. The resulting invariant joint distribution $\Gamma_{m, n}$ over multi-industry presence $m$ and firm product count $n$ is described in Appendix A.

Forward-Looking Firms For expositional purposes, in the previous section we described the model with myopic firms that maximize their one-period-ahead returns. For the rest of our analysis, we relax this assumption and consider firms that maximize the discounted sum of future returns. The analysis of this new model is very similar to that of the previous model except that the returns to innovation take the form of a value function that takes into account all future contingencies. The following proposition provides the exact forms of the value of a firm that has a productivity portfolio $\hat{\mathbf{q}}$ and operates in $m$ industries.

Proposition $\mathbf{2}$ Let the value of a firm with a productivity portfolio $\hat{\mathbf{q}}$ in $m$ industries be denoted by $\mathcal{V}(\hat{\mathbf{q}}, m)$. This value is equal to

$$
\mathcal{V}(\hat{\mathbf{q}}, m)=\frac{Z}{M}\left[\sum_{\hat{q} \in \hat{\mathbf{q}}} V(\hat{q})+n V_{m}\right]
$$


where

$$
V(\hat{q})=\frac{\hat{q}^{\epsilon-1}}{\varepsilon[r+\tau+\kappa+g(\epsilon-2)]}
$$

and

$$
(r-g) V_{m}=\max _{a, b}\left\{\begin{array}{c}
\left.-\tilde{w}\left[h_{a}(a)+h_{b}(b)+\mathbf{1}_{(b>0)} \phi\right]\right] \\
+a\left[\alpha V^{H}+(1-\alpha) V^{C}+V_{m}\right]+b\left(1+\rho_{m}\right)\left[V^{H}+V_{m}\right] \\
+x\left(1-\frac{m}{M}\right)\left[V_{m+1}-V_{m}\right]-\tau V_{m}+\kappa \mathbb{E}_{\hat{q}} V\left(\hat{q}_{t}\right)
\end{array}\right\} .
$$

The analogous production values are defined as $V^{H} \equiv \mathbb{E}_{\hat{q}, \eta}^{H} V(\hat{q}+\eta)$ and $V^{C} \equiv \mathbb{E}_{\hat{q}, \lambda}^{C} V(\hat{q}+\lambda)$.

Proof. See Appendix A

This important result has a number of implications. First, the value of a firm has a tractable additive form across product lines. Moreover, the firm value has two major components: the first component is the production value $V(\hat{q})$, which simply computes the sum of the future discounted profits where the effective discount rate takes into account the rate of creative destruction $\tau$, the exogenous destruction rate $\kappa$, and the obsolescence of the relative productivity $\hat{q}$ due to the growth of $\bar{q}$. The second component is the $\mathrm{R} \& \mathrm{D}$ option value $V_{m}$, which is a direct function of the multi-industry presence due to the associated internalization of spillovers. Finally, because of the stochastic nature of step sizes, the expectations now integrate over the productivity (which are type specific) and step size.

Welfare Finally, we close this section by describing the SBGP equilibrium welfare. In an SBGP equilibrium that has an initial consumption $C_{0}$ and a growth rate of $g$, welfare is computed as

$$
W\left(C_{0}, g\right)^{S B G P}=\int_{0}^{\infty} \exp (-\delta t) \frac{\left(C_{0} e^{g t}\right)^{1-\gamma}}{1-\gamma} d t=\frac{1}{1-\gamma}\left(\frac{C_{0}^{\frac{1-\gamma}{\varepsilon-1}}}{\rho-(1-\gamma) g}-\frac{1}{\rho}\right)
$$

We will report our results in consumption-equivalent terms. In particular, when two different public policies $T_{1}$ and $T_{2}$ generate different SBGP equilibrium welfare values as $W\left(C_{0}^{T_{1}}, g^{T_{1}}\right)$ and $W\left(C_{0}^{T_{2}}, g^{T_{2}}\right)$, we will report $\beta$ such that

$$
W\left(\beta C_{0}^{T_{1}}, g^{T_{1}}\right)=W\left(C_{0}^{T_{2}}, g^{T_{2}}\right)
$$

In other words, $\beta$ constitutes the compensating differential in initial consumption that equalizes the welfare of the two proposed policy environments. It therefore provides an intuitive measure for evaluating policy tools. This completes the description of the theoretical environment. Now we are ready to move on to the quantitative analysis.

\section{Quantitative Analysis}

To test and estimate our model, we rely on a unique combination of datasets on French innovative firms between 2000 to 2006. The final sample is composed of 13,708 firm-year observations, for which we provide descriptive statistics in Table 12 of Appendix B. Details regarding data sources, and data organization are provided in Appendix B. 


\subsection{Data}

R\&D Information Information about research investment comes from the annual R\&D Survey conducted by the French Ministry of Research. The survey is conducted in annual waves of crosssectional data, and covers a representative sample of French firms of more than 20 employees investing in $R \& D$. The questionnaire includes extensive information about the financing of $R \& D$. It not only breaks down R\&D investment according to the source of the funds but also provides its allocation to different types of research. The distinction between basic and applied research is based on the Frascati manual, and is therefore similar to the NSF definition presented in the introduction

Multi-Industry Activity To measure multi-industry presence, we count the number of distinct SIC codes in which a firm is present. Our data allow us to identify a firm's links to different industries not only through product lines within the same firm but also through its majority ownership links. We use "Enquete Liaisons Financieres" (LIFI) to identify multiple activities within the same business group. In addition, we use "Enquete Annuelle des Entreprises" (EAE) to identify multiple activities within the same firm.

The LIFI data is based on a yearly survey by INSEE. It covers all economic activities but restricts its attention to firms that either employ more than 500 employees or generate more than 60 million euros in revenue, or hold more than 1.2 million euros of traded shares. However, since 1998 the survey is cross-referenced with information from Bureau Van Dijk and thus covers almost the whole economy. The LIFI survey contains information that makes it a unique data set for studying multi-market activity. Besides providing information on direct financial links between firms, it also accounts for indirect stakes and cross-ownership when identifying the head of the group. This is important as it allows us to precisely reconstruct the group structure even in the presence of pyramids. This feature allows us to obtain a reliable account of the structure of business groups in the French economy and, as a consequence, reliable measures of our key variable, their multi-market presence.

Since, at the same time, each firm can also operate in several markets, we cross-reference the data set with the EAE survey by the Ministry of Industry ("Enquete Annuelle des Entreprises"). The survey is filled out by French firms with more than 20 workers and contains information not only on the different markets in which a firm operates but also information on market dedicated sales for each segment. The data cover the vast majority of French firms and span the period 2000-2006.

Balance-Sheet Information We use the firm- and industry-level data sets based on accounting data extracted again from the EAE files. The data also include unique firm identifiers allowing us to match them to the R\&D and LIFI data.

\subsection{Computer Algorithm Outline}

An equilibrium of this model is described by a system of five equations in the five variables $\left(\tau_{a}, \tau_{b}^{e}, \tau_{b}^{d}, \tilde{w}, g\right)$. This system can be evaluated using the following procedure: 
1. Calculate $\alpha$ and the distribution of $\hat{q}$ using $\tau_{a}, \tau_{b}^{e}, \tau_{b}^{d}$, and $g$ according to equations (1) and (15).

2. Calculate $g$ using, $\tau_{a}, \tau_{b}$, and the distribution over $\hat{q}$ with equation (20).

4. Calculate $V^{H}=\mathbb{E}_{\hat{q}, \eta}^{H} V(\hat{q}+\eta)$ and $V^{C}=\mathbb{E}_{\hat{q}, \lambda}^{C} V(\hat{q}+\lambda)$ using the relevant step size distribution and the type-specific productivity distributions.

5. Find $a_{m}$ and $b_{m}$ using first-order conditions with $\tilde{w}$ from equation (21).

6. Impose an upper bound on $n$ and find the steady state $\Gamma_{m, n}$ using the flow equations in A.

7. Compute the updated values of $\tau_{a}, \tau_{b}^{e}$, and $\tau_{b}^{d}$ using (16) and (14).

8. The difference between the conjectured and updated values of $\tau_{a}, \tau_{b}^{e}, \tau_{b}^{d}$, and $g$ in conjunction with the labor market clearing differential from (18) constitute the five desired equations.

We use Powell's (Powell (1970)) hybrid equation solver to solve this set of equations for a given set of parameters. To minimize the SMM objective function, we perform a search over the parameter space using a combination of a naive simulated annealing algorithm and a Nelder-Mead simplex (Nelder and Mead (1965)) algorithm. See Zangwill and Garcia (1981) for more information on solving systems of nonlinear equations.

\subsection{Estimation}

In this section we describe the estimation strategy used. We will assume that the fixed costs are drawn from a lognormal distribution $\mathcal{B}(\phi)$ with mean $\bar{\phi}$ and variance $\sigma^{2}$. As a result, the set of parameters of the model is

$$
\theta=\left\{\delta, \gamma, \varepsilon, p, \eta, \lambda, E, U, \nu_{a}, \nu_{b}, \xi_{a}, \xi_{b}, \kappa, \bar{\phi}, \sigma, \zeta, \varsigma\right\} \in \Theta
$$

In our data set, for each firm $f$ and each time period $t$, we have a vector of $N$ observables from the actual data $\mathbf{y}_{f t} \equiv\left[y_{f t}^{1} \cdot \cdots \cdot y_{f t}^{N}\right]_{N \times 1}^{\prime}$ including the number of industries in which the firm is present, sales, profits, and labor costs. Let the entire data set be denoted by $\mathbf{y}$.

We use the simulated method of moments (SMM) for the estimation. ${ }^{8}$ Define $\Lambda(\mathbf{y})$ and $\Lambda(\theta)$ to be, respectively, the vectors of real data moments (generated from $\mathbf{y}$ ) and equilibrium model moments (generated for some vector of parameters $\theta$ ). Since certain moments require knowledge of the joint distribution of firms over the number of products and industries $(m, n)$ and the portfolio of product qualities $\mathbf{q}$, which has no apparent analytic form, we simulate a large panel of firms to calculate $\Lambda(\theta)$ to a high degree of accuracy. ${ }^{9}$

Our proposed estimator minimizes a quadratic form of the difference between these two vectors

$$
\widehat{\theta}=\arg \min _{\theta \in \Theta}[\Lambda(\theta)-\Lambda(\mathbf{y})] \cdot W \cdot[\Lambda(\theta)-\Lambda(\mathbf{y})]
$$

\footnotetext{
${ }^{8}$ See Bloom (2009) and Lentz and Mortensen (2008) for further description and usage information on SMM.

${ }^{9}$ For our results, we simulate $32 \mathrm{~K}$ firms with a burn-in time of 100 years and 100 time steps per year.
} 
where $W$ is the weighting matrix. We use a diagonal weighting matrix with entries equal to the inverse square of the data moment value, or in notational terms $W_{i i}=1 / \Lambda_{i}(\mathbf{y})^{2}$ and $W_{i j}=0$ for $i \neq j$. In our estimation, we use 26 moments which we denote as $\Lambda(1)-\Lambda(26)$. We pick moments that are most informative for the unique features of our model.

Status Quo Policies We also take into account that, during the period we consider, there was existing government support for R\&D activities in France. In our data set $10 \%$ of coporate $R \& D$ is, on average, publicly funded. Therefore in our estimation, we introduce a uniform subsidy to the total $\mathrm{R} \& \mathrm{D}$ spending of the firm $\psi=0.10$. The government has a balanced budget every period, so that the sum of total subsidies $(S)$ and public research funding $(R)$ must be equal to tax revenues, that is

$$
T=S+R=\psi\left[\sum_{m=1}^{M} \mu_{m} C_{B}\left(b_{m} \mid \phi\right)+C_{A}(a)\right]+U C_{B}(u \mid \bar{\phi})
$$

where $T$ is a lump-sum tax on consumers. In France, during 2000-2006, the fraction of GDP devoted to public research labs and academic institutions was approximately $0.5 \%$. Therefore, we pick $R / Z$, which is the share of GDP devoted to public basic research, to be $0.5 \%$.

\subsection{Identification}

In this section we explain the moments that are used to identify our parameters. Since we are minimizing the weighted distance between the theoretical and empirical moments according to the objective function in (22), all parameters are identified jointly. Nevertheless, given the dynamics in our model, we can still provide a heuristic discussion of identification. In Appendix E Table 15, we provide a Jacobian matrix that reports the sensitivity of each moment to each parameter. This way, we verify, at least locally, that the moments that we use to identify certain parameters are indeed informative.

Note that here $\hat{m}$ denotes the number of industries in which a firm has one or more products, rather than the number of industries in which the firm has working knowledge $(m)$. Since $m$ is not directly observable, we must compute the distribution over $\hat{m}$ through simulation to in order to match the data.

Basic Research Intensity by Number of Industries, $\Lambda(1-8)$ : We define basic research intensity as the ratio of spending on basic research to spending on applied research. Since the effect of multi-industry presence on this quantity is of critical importance to our model, we have one moment for each $\hat{m} \in\{1, \ldots, M\}$. Given a set of parameters and an equilibrium of the model, this moment's value for a given $\hat{m}$ is

$$
\Lambda(1-8)=\mathbb{E}_{m}\left[\frac{\bar{h}_{b}^{m}}{h_{a}^{m}} \mid \hat{m}\right]
$$

In our estimation, we use $M=10$. However, in the data there are only a handful of firms with $\hat{m}>8$, so we have one moment for each $\hat{m} \in\{1, \ldots, 7\}$ and a final moment which is averaged over $\hat{m} \in\{8,9,10\}$. The way in which this moment increases with $\hat{m}$ identifies the cross-industry spillover 
Figure 6: Basic Research Intensity vs Spillover Parameter $p$

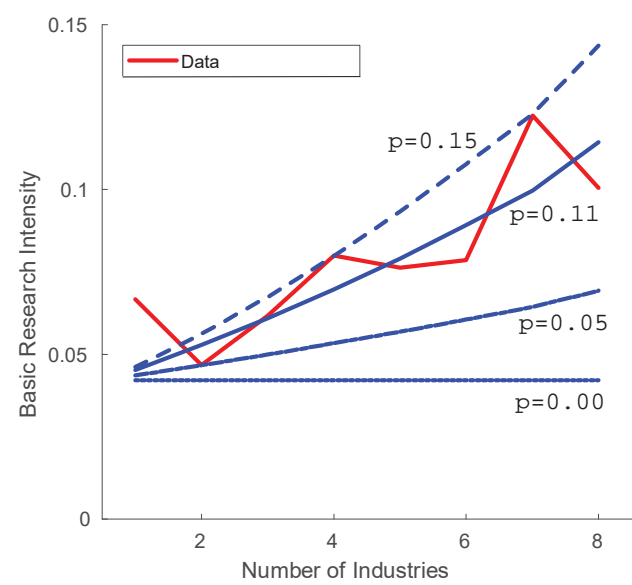

Table 2: Basic Research And Multi-Market ACtivity

\begin{tabular}{lcccc}
\hline \hline & 1-Digit SIC & 2-Digit SIC & 3-Digit SIC & 4-Digit SIC \\
\hline Log \# of Industries & $\begin{array}{c}0.032^{* * *} \\
(0.01)\end{array}$ & $\begin{array}{c}0.027^{* * *} \\
(0.00)\end{array}$ & $\begin{array}{c}0.024^{* * *} \\
(0.00)\end{array}$ & $\begin{array}{c}0.021^{* * *} \\
(0.00)\end{array}$ \\
Log Employment & $0.003^{* *}$ & 0.002 & 0.001 & 0.001 \\
& $(0.00)$ & $(0.00)$ & $(0.00)$ & $(0.00)$ \\
\hline Year \& Organization F. E. & YES & YES & YES & YES \\
$\mathrm{N}$ & 13708 & 13708 & 13708 & 13708 \\
\hline \hline Notes: Pooled data for the period 2000-2006. Estimates are obtained using \\
Tobit models and relate to the marginal effect of the regressors at the sample \\
mean. Basic Research Intensity is defined as the ratio of total firm investment \\
in basic research divided by total firm investment in applied research. Log \# \\
of Industries is the number of distinct SIC codes in which a firm is present. \\
Year FE denotes year fixed effects, and Organization FE denotes whether \\
the firm operates its activity as a conglomerate or as a business group. See \\
the Appendix for the definition of variables. Robust standard errors clustered \\
at the firm level are in parentheses. One star denotes significance at the 10\% \\
level, two stars denote significance at the 5\% level, and three stars denote \\
significance at the 1\% level.
\end{tabular}

parameter $p$ in our model. Additionally, the overall level provides us with some identification power for the basic research cost parameters $\left(\xi_{b}, \nu_{b}\right)$.

Figure 6 plots the empirical (red line, which is the same as Figure 2 in the Introduction) and model counterparts for these moments for different spillover parameter $p=\{0.00,0.05,0.11,0.15\}$. The figure makes it clear that our cross-industry spillover parameter $p$ is identified by matching the basic research intensity of multi-industry firms.

Table 2 provides further evidence about the relationship between multi-industry presence and basic research intensity, controlling for size. To account for zeros in the the dependent variable, we estimate a Tobit model. In all specifications basic research intensity is increasing in the number of industries. According to the benchmark estimation, presence in an additional industry increases a firm's basic research intensity by 3 percentage points on average. In terms of magnitude, this corresponds to a $50 \%$ increase in the average basic intensity of a single industry firm. ${ }^{10}$

Extensive Margin of Basic Research Investment by Number of Industries, $\Lambda(9-16)$ : We use the share of positive basic research spending by each $\hat{m}$ to identify the mean $\bar{\phi}$ and variance $\sigma^{2}$ of the fixed cost distribution basic research. This is simply the probability that the idiosyncratic fixed cost draw is less than the cutoff for a certain $\hat{m}$

$$
\Lambda(9-16)=\mathbb{E}_{m, \phi}\left[\mathbf{1}_{\left(\phi<\phi_{m}^{*}\right)} \mid \hat{m}\right]
$$

Though not plotted here, one can see in the Jacobian matrix in Table 15 that the average fixed cost parameter $\bar{\phi}$ strongly influences the level of this moment for all values of $\hat{m}$. Furthermore, the fixed cost variance parameter $\sigma$ induces a tilt in these moments across different $\hat{m}$ values. That is to say, increasing $\sigma$ raises the probability of performing basic research for low $\hat{m}$ firms an lowers it for high

\footnotetext{
${ }^{10}$ Table 14 in Section D of the Appendix provides a rich set of robustness checks in terms of control variables, alternative measures of multi-industry presence, and estimation methods. Most important, it exploits historical ownership structures and changes in government policies as instrumental variables. The IV estimates are larger in magnitude and seem to suggest that the positive correlation is not driven by omitted variables.
} 
$\hat{m}$ firms. This is consistent with the intuition of the model and with the properties of the lognormal distribution.

Distribution of $\mathbf{m}, \Lambda(\mathbf{1 7 - 1 8})$ : We track two moments relating to the distribution of $\hat{m}$, the mean and mean squared. They are given by

$$
\Lambda(17)=\mathbf{E}_{\hat{m}}[\hat{m}] \quad \text { and } \quad \Lambda(18)=\mathbf{E}_{\hat{m}}\left[\hat{m}^{2}\right]
$$

Looking to the Jacobian matrix, one can see that the mean $m$ value and the mass of potential entrants are closely linked, as successful entrants start with the lowest working knowledge value $m=1$. Similarly, the mean of $m^{2}$ is strongly influenced by the entrant buyout probability parameter $\varsigma$. Intuitively, when entrants are more likely to be bought out by incumbents, which results in industry expansion with probability $z$, this will concentrate industry expertise in existing firms, thus increasing the dispersion of $m$.

Empirically, we calculate the share of firms as a function of the number of 1-Digit SIC industries, which is the number of distinct SIC codes in which a firm is present. On average firms are present in 2 distinct industries as defined by 1-digit SIC codes. Although nearly $44 \%$ of the firms are operating in only one industry, the remaining firms occupy a large spectrum of industries. The full distribution is plotted in Figure 7, and the results are very similar when using more disaggregate SIC classifications (up to the 4-digit SIC level) or when changing the definition of an industry link. ${ }^{11}$

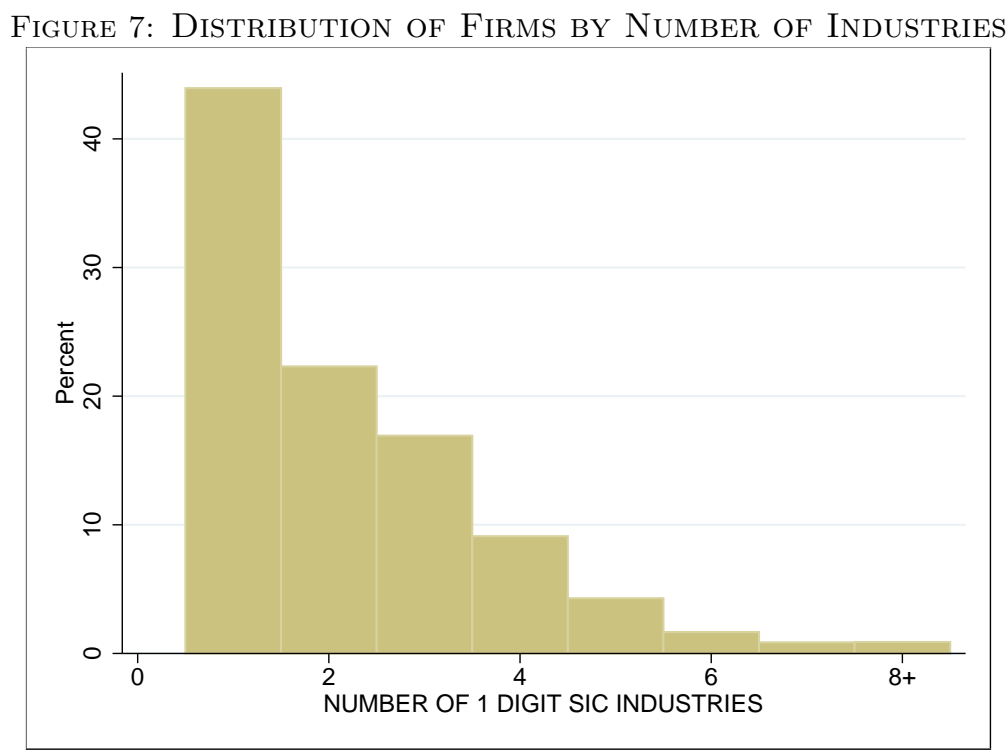

\footnotetext{
${ }^{11}$ Figures available upon request.
} 
Profitability, $\Lambda(\mathbf{1 9})$ : Firm profitability is defined as the ratio of profits to sales. For a given panel of firms, this moment is given by

$$
\Lambda(19)=\frac{1}{\varepsilon}-\mathbb{E}_{m, n, \hat{\mathbf{q}}}\left[\frac{\tilde{w}\left[h_{a}^{m}+\bar{h}_{b}^{m}\right]}{\frac{1}{n} \sum_{i} \hat{q}_{i}^{\varepsilon-1}}\right]
$$

Notice that there is one fixed component from static production side that yields information on the value of $\varepsilon$ and another from dynamic $R \& D$ expenditures that yields information on $R \& D$ cost and step size parameters. Consistent with this, though this moment value arises from a multitude of factors, the major determinants are $\varepsilon$ and the various fixed and variable $\mathrm{R} \& \mathrm{D}$ cost parameters.

Exit Rate, $\Lambda(20)$ : As exit occurs when firms either receive the exogenous destruction shock or lose their last product, the predicted exit rate will be

$$
\Lambda(20)=\kappa+\tau \cdot \sum_{m} \Gamma_{m, 1}
$$

However, for consistency, we simply use the value from the simulated firm sample. This moment serves primarily to determine the value of the rate of exogenous destruction $\kappa$. Additionally, as the bulk of equilibrium creative destruction $\tau$ arises from applied research, this also provides information on the applied R\&D cost parameters $\nu_{a}$ and $\xi_{a}$.

Total Research Intensity, $\Lambda(\mathbf{2 1})$ : We have one moment to track the level of R\&D overall: the ratio of total research labor expenditures spending to total production labor expenditures. Since research spending is proportional to $n, \mathrm{R} \& \mathrm{D}$ expenditures per product will be the same across firms with the same $m$, while employment will be a function of the portfolio of product qualities. Because the wage is common to both types of labor, this will simply be the ratio of $\mathrm{R} \& \mathrm{D}$ employment to production employment given by

$$
\Lambda(21)=\mathbb{E}_{m, n, \hat{\mathbf{q}}}\left[\frac{\tilde{w}\left[h_{a}^{m}+\bar{h}_{b}^{m}\right]}{\left(\frac{\varepsilon-1}{\varepsilon}\right) \frac{1}{n} \sum_{i} \hat{q}_{i}^{\varepsilon-1}}\right]
$$

Conditional on innovation rates, this moment give us information on cost side of R\&D, namely the research production function parameters, as well the benefit side, in the form of innovation step sizes for basic and applied research, $\eta$ and $\lambda$ (see Table 15).

Firm Growth, $\Lambda(\mathbf{2 2})$ : We have a moment for employment growth amongst firms. This is calculated conditional on the firm not exiting, since we do not observe the last period's growth rate for exiting firms. The moment is calculated by looking at the one-year growth rate of total employment by a firm. This moment is sensitive to the overall rates of exit and creative destruction, and as such, yields information on a broad array of parameters. As seen in Table 15, one parameter for which it shows particular distinction is the CRRA parameter $\gamma$. 
Aggregate Growth, $\Lambda(\mathbf{2 3})$ : The aggregate growth rate gives information on the effectiveness of research spending absent effects coming from the distribution of firm size and its relation to firm growth, particularly on innovation step sizes.

In our model the household's welfare depends crucially on the level of aggregate growth, and hitting that moment is of particular importance. For that purpose, we boost the weighting on the aggregate growth moment. ${ }^{12}$

Within-industry Spillover (Hot vs Cold Product Lines), $\Lambda(\mathbf{2 4})$ : $\quad$ In order to quantify the spillovers associated with basic research, we turn to patent citation data. The model predicts that innovations that build off of previous basic research should have a larger step size on average. If we take citations as a proxy for step size, then patents that cite basic research should themselves have more citations.

This effect will diminish with the age of the patent due to product line cooldown. Thus the average time after which a public innovation is indistinguishable from a private innovation should be

$$
\Lambda(24)=\frac{1}{\zeta}\left(\frac{\tau_{a}}{\tau}\right)
$$

This yields direct information on the value of the cooldown rate $\zeta$, as seen in the Jacobian matrix.

To estimate the cooldown rate of innovations deriving from basic research, we use the NBER patent data set covering the period 1974-2006. Two empirical issues need to be addressed: $(i)$ distinguishing patents derived from basic and applied research, and $(i i)$ capturing the idea of successively less original contributions. We address the first point by distinguishing between patents applied for by corporations from patents applied for by public institutions. We address the second point by computing a citationbased measure of the marginal contribution of citing patents over time. ${ }^{13}$

For each patent we first identify citing patents across time. For each of the citing patents we then compute their cumulative 10-years-forward citations. Our measure, Quality of Citing Patents, captures the marginal importance of each successive citing patent. Table 3 tests the mean difference of this measure between patents originated in the public sector, and patents originated in the private sector.

Table 3 confirms that public patents are followed up by higher quality patents relative to private patents. The difference oscillates between 0.3 to 0.7 citations, and is statistically significant in the first 7 years. The importance of citing patents is stable until the original public patent is 8 years old, at which point there is a significant drop in citations of citing patents from 2.4 to 1.7 . This is when the difference between private and public, in terms of citations, becomes economically and

\footnotetext{
${ }^{12}$ Increasing the weighthing factor to 3 was sufficient to align the aggregate growth rate in the data and the model.

${ }^{13}$ The use of US patent data was linked to the availability for a long time horizon of publicly available data on patents granted, depositor classification, and the associated citations. The analysis of our final data set will focus exclusively on French patenters but the construction of the different variables uses information from the entire data set. While our proxy is simple to measure in the data, it potentially misclassifies the contribution of private basic patents. However, given that our interest lies in the relative difference between those two groups of patents across time, time invariant errors in the classification should not impact our conclusions. Appendix C provides a more detailed explanation of the construction of the variables.
} 
Table 3: Citation Differences for Public and Private Patents

\begin{tabular}{lcccccccccc}
\hline \hline Age & 1 & 2 & 3 & 4 & 5 & 6 & 7 & 8 & 9 & 10 \\
\hline Difference & $.3^{* *}$ & $.3^{* *}$ & $.62^{* * *}$ & $.28^{* *}$ & $.41^{* *}$ & .23 & $.71^{* * *}$ & .08 & .39 & .14 \\
& $(0.15)$ & $(0.15)$ & $(0.17)$ & $(0.14)$ & $(0.18)$ & $(0.17)$ & $(0.25)$ & $(0.16)$ & $(0.25)$ & $(0.24)$ \\
\hline \hline
\end{tabular}

Notes: Differences in citation patterns of 15383 patents granted by the USPTO to French private (92\%) and public (8\%) depositors. The difference is computed in terms of Quality of Citing Patents across patent age. Quality of Citing Patents is computed as the 10-years-forward citations of the citing patents and is measured for patents granted in the period 19751985. Two sample t-test with unequal variances were used. One star denotes significance at the $10 \%$ level, two stars denote significance at the $5 \%$ level, and three stars denote significance at the $1 \%$ level.

statistically non-significant. The results are similar when using the Wilcoxon-Mann-Whitney test. This time pattern will yield direct information on the value of the cooldown rate $\zeta$.

Firm Age, $\Lambda$ (25-26): Firm age is highly correlated with firm size. We track the average age of firms for those above and below the median firm size. This yields information entry and exit patterns, as well as on the rate of creative destruction. Moment $\Lambda(25)$ is the average age of firms below the median firm size, while moment $\Lambda(26)$ is the average age for those firms above it.

\subsection{Estimation Results}

Table 4 reports the values of the estimated structural parameters. The estimated values of the discount rate and CRRA utility parameters are within their standard macro ranges. The elasticity of substitution parameter generates $17 \%(=1 / \varepsilon)$ gross profits, resulting in $7.9 \%$ net profits after subtracting $\mathrm{R} \& \mathrm{D}$ expenses as a share of sales.

Table 4: Parameter Estimates

\begin{tabular}{clcc||clcc}
\hline \hline$\#$ & Description & Sym & Value & $\#$ & Description & Sym & Value \\
\hline 1. & Discount Rate & $\delta$ & 0.038 & 9. & Applied Cost Curvature & $\nu_{a}$ & 1.367 \\
2. & CRRA Utility Parameter & $\gamma$ & 2.933 & 10. & Basic Cost Curvature & $\nu_{b}$ & 1.538 \\
3. & Elasticity of Substitution & $\varepsilon$ & 5.800 & 11. & Applied Cost Scale & $\xi_{a}$ & 1.228 \\
4. & Cross-industry Spillover & $p$ & 0.113 & 12. & Basic Cost Scale & $\xi_{b}$ & 5.437 \\
5. & Basic Step Size & $\eta$ & 0.079 & 13. & Exogenous Exit Rate & $\kappa$ & 0.006 \\
6. & Applied Step Size & $\lambda$ & 0.049 & 14. & Basic Fixed Mean & $\bar{\phi}$ & -4.761 \\
7. & Mass of Entrants & $E$ & 0.502 & 15. & Basic Fixed Std. Dev. & $\sigma$ & 0.327 \\
8. & Mass of Academic Labs & $U$ & 0.491 & 16. & Product Cooldown Rate & $\zeta$ & 0.116 \\
& & & 17. & Buyout Rate & $\varsigma$ & 0.454 \\
\hline \hline
\end{tabular}

One of the most important parameters of our model is the cross-industry spillover parameter $p=0.11$, which measures the probability that a basic innovation will have an additional immediate application. This estimate affects the extent to which basic innovations contribute to cross-sectional growth. In equilibrium, firms operate in two industries out of 10 on average. Therefore, any given spillover is not embodied with probability $89 \%(=8 / 9)$. Given that the probability of having a spillover is $11 \%$, the probability of having a disembodied spillover is $10 \%(=0.11 * 0.89)$.

The estimated innovation size of basic research is $\eta=7.9 \%$ and the innovation size of each new applied innovation is $\lambda=4.9 \%$. This implies that basic research (hot product lines) makes applied 
innovation $60 \%(=7.9 / 4.9-1)$ more productive.

Additionally, each basic innovation has a within-industry spillover. The cool-down rate of hot product lines is estimated to be $\zeta=0.12$, which indicates that a basic innovation affects the subsequent innovations in the same product line for almost $8.3(=1 / 0.12)$ years on average.

The elasticity of applied innovation counts with respect to the research dollars spent is estimated to be $0.73\left(=1 / \nu_{a}\right)$ and similarly the elasticity of basic innovation with respect to the basic research investment is $0.65\left(=1 / \nu_{b}\right)$. These values are close to the elasticity estimates in the literature, which typically finds a value around 0.5 (Griliches (1990), Pakes and Griliches (1984) and Kortum (1992, 1993)).

\subsection{Goodness of Fit}

In this section, we will first focus on the moments that we targeted in our estimation and then turn to the moments that we did not directly target but still find useful in understanding the model's performance.

Targeted Moments Table 5 contains the moments from the actual data and our estimated model.

Table 5: Moments Used in Estimation

\begin{tabular}{clcc||clcc}
\hline \hline$\#$ & Description & Model & Data & $\#$ & Description & Model & Data \\
\hline$\Lambda(1-8)$ & Basic Research Extensive & \multicolumn{2}{c||}{ See Figure 9 } & $\Lambda(21)$ & R\&D/Labor & 0.284 & 0.260 \\
$\Lambda(9-16)$ & Basic Research Intensive & \multicolumn{2}{c}{ See Figure 8} & $\Lambda(22)$ & Employment Growth & 0.111 & 0.103 \\
$\Lambda(17)$ & Mean Industries & 2.217 & 2.203 & $\Lambda(23)$ & Aggregate Growth & 0.013 & 0.015 \\
$\Lambda(18)$ & Mean Square Industries & 7.213 & 6.975 & $\Lambda(24)$ & Spillover Differential & 8.378 & 8.000 \\
$\Lambda(19)$ & Return on Sales & 0.032 & 0.032 & $\Lambda(25)$ & Age, Small Firms & 11.53 & 14.99 \\
$\Lambda(20)$ & Exit Rate & 0.082 & 0.091 & $\Lambda(26)$ & Age, Large Firms & 18.69 & 24.87 \\
\hline \hline
\end{tabular}

The results indicate that the model performs very well in generating firm and industry dynamics similar to those in the data. Consistent with our data, a significant fraction of innovating firms invest in basic research. In particular, $29 \%$ of firms are investing in basic research, which was $27 \%$ in the data. We also capture the positive relationship between the extensive margin of basic research and multi-industry presence, as evidenced in Table 5 and Figure 8.

The positive correlation between multi-industry presence of a firm and its basic research intensity was one of the major predictions of our model. As explained previously in the text, multi-industry presence plays an important role in increasing basic research incentives, by allowing a greater potential to internalize the positive spillovers from basic research. In our reduced-form analysis, we confirmed the significant and positive correlation between multi-industry presence and basic research intensity. This has been the key moment to identify the cross-industry spillover parameter. Our model successfully generates this positive correlation.

In the data, firms operate on average in 2.2 industries, and the same is true in the model. Furthermore, we find the mean squared in the model to be 7.2 , compared to 7.0 observed in the data. 

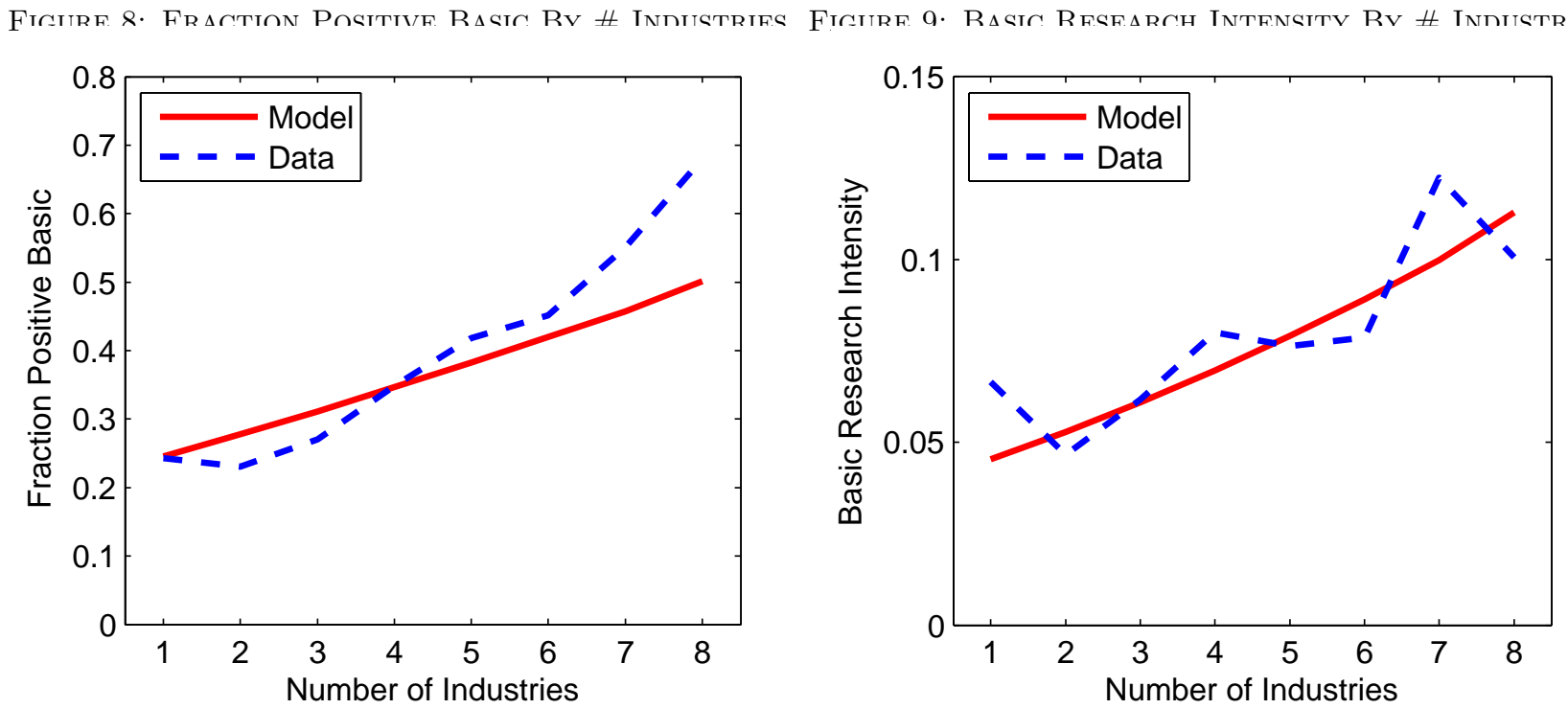

In addition, the mean profitability is $3.2 \%$ in the model and in the data. The prime determinants of profitability are the step sizes for basic and applied innovation. However, these also affect the investment levels for both types of research, since this increases the return to successful innovation. Therefore, the step size parameters are set to be a compromise between hitting the profitability moment and the research investment and growth moments.

We are targeting additional moments regarding research investments. The first is the average ratio of total research labor to production labor by incumbent firms. The model comes very close to hitting this ratio exactly $(28.4 \%$ vs $26.0 \%$ ), largely in order to hit the aggregate growth and return on sales.

All of these components of the economy determine the aggregate growth rate. Our model matches the observed growth rate closely. Our model economy grows at a rate of $1.3 \%$, while the French economy grew at an average rate of $1.5 \%$ during the period studied (2000-2006).

Untargeted Moments In this part, we discuss our model's prediction about some of the moments that we did not directly target.

Interestingly, in the data the correlation between profitability and basic research intensity is not significantly different from zero. The same implication emerges from our model. In the baseline model, the correlation between profitability and basic research intensity is only 0.04. This result emerges because basic research investment is determined through the multi-industry presence of the firms, whereas profitability is determined by the share of hot and cold product lines, type of research investment, and the productivity distribution $\mathcal{F}(\hat{q})$ in the economy.

Our model naturally generates a positive correlation between multi-industry presence and firm size, which is also empirically true in the data. This arises since both of these moments are strongly correlated with firm survival. In the model, we find a correlation of 0.52 between the log employment and multi-industry presence. In the data, this value is 0.76 .

Another stylized fact in our data is that the firm size distribution is highly skewed. This is a well- 
known feature that is documented extensively in the literature. For detailed references, see Aghion, Akcigit, and Howitt (2014). In our model, we capture this fact with a skewness of the firm size distribution of 4.12 . This value is 3.07 in the data.

Our estimates indicate that entrants play an important direct role in overall growth. The innovation rate from entrants is $0.43 \%$, whereas that number is $0.92 \%$ for incumbents. That implies that entrants account for $32 \%$ of growth. Though our number is for the French economy, our number is in line with Foster, Haltiwanger, and Krizan (2001) who find that $25 \%$ of productivity growth in the US comes from new entry.

We will now focus on the details of the equilibrium and the social planner's problem to study the efficiency properties of this economy. Then we will turn to various policies that could address this inefficiency.

\subsection{Status Quo: Baseline Economy}

Table 6 provides equilibrium values for some of the important variables in the model:

Table 6: Decentralized Economy: Endogenous Variables (in Percentages)

\begin{tabular}{ccccccccccccc}
\hline \hline$\psi$ & $R / Z$ & $\tau_{a}$ & $\tau_{b}^{e}$ & $\tau_{b}^{d}$ & $L_{p}$ & $L_{b}$ & $L_{u}$ & $L_{e}$ & $L_{a}$ & $\alpha$ & $g$ \\
\hline $\begin{array}{c}\text { subsidy } \\
\text { rate }\end{array}$ & $\begin{array}{c}\text { public } \\
\text { basic } \\
\text { in GDP }\end{array}$ & $\begin{array}{c}\text { applied } \\
\text { innovation }\end{array}$ & $\begin{array}{c}\text { embodied } \\
\text { basic } \\
\text { innovation }\end{array}$ & $\begin{array}{c}\text { disembodied } \\
\text { basic } \\
\text { innovation }\end{array}$ & $\begin{array}{c}\text { production } \\
\text { labor }\end{array}$ & $\begin{array}{c}\text { labor in } \\
\text { private } \\
\text { basic }\end{array}$ & $\begin{array}{c}\text { labor in } \\
\text { public } \\
\text { basic }\end{array}$ & $\begin{array}{c}\text { entrant } \\
\text { labor }\end{array}$ & $\begin{array}{c}\text { labor in } \\
\text { private } \\
\text { applied }\end{array}$ & $\begin{array}{c}\text { share } \\
\text { of hot } \\
\text { product lines }\end{array}$ & $\begin{array}{c}\text { growth } \\
\text { rate }\end{array}$ & $\begin{array}{c}\text { welfare } \\
\text { prate }\end{array}$ \\
\hline 10 & 0.5 & 22.0 & 0.58 & 0.28 & 85.6 & 0.53 & 0.52 & 4.5 & 8.9 & 6.9 & 1.34 & 100.0 \\
\hline \hline
\end{tabular}

In this table, $\tau_{a}$ denotes the aggregate rate of applied innovation by incumbents and entrants, whereas $\tau_{b}^{e}$ and $\tau_{b}^{d}$ denote the aggregate rates of embodied and disembodied basic innovation, respectively. The next five columns report the labor allocations into production, private basic, public basic, entry, and applied research. The remaining columns report the fraction of hot product lines $\alpha$, the growth rate $g$, and the welfare in consumption equivalent terms $\beta$.

In our benchmark economy, $85.6 \%$ of labor is used for production, and $14.4 \%$ is employed for innovation activities. Among researchers, roughly $7 \%$ are engaged in basic research activities. Note that this composition within innovation activities will be the central focus of the policy analysis, since uninternalized (potential) spillovers are one of the main sources of inefficiency. In order to the study the welfare properties of this economy, we normalize the benchmark welfare to $\beta=1.00$ and compare it to the social planner's optimum, which we will analyze next.

\subsection{Quantifying the Social Planner's Optimum}

In this section, we provide the solution to the social planner's problem. Recall that while the basic innovation done by the private sector turns into a consumer product immediately, those done by the public sector (e.g., universities) come from the "Ivory Tower" and turn into a consumer product with some delay. In order for this to happen, a private firm must do some applied innovation that builds on the basic knowledge, which happens after 5 years on average $\left(=1 / \tau_{a}=1 / 0.22\right)$. This introduces 
the possibility that policies relating to public-private sector partnerships or patenting rights of public researchers could reduce this delay. We will consider this case in Section 5.

Before going into the details of the solution, it may be useful to provide an overview of the potential inefficiencies present in this economy, both static and dynamic:

1. monopoly distortions on the production side,

2. (in)efficient applied research investment by private firms,

3. (in)efficient basic research investment by private firms,

4. (in)efficient basic research investment by public research labs,

5. (in)efficient level of entry.

Since our focus is on innovation policies, we consider a social planner who controls the R\&D production in the economy while being subject to the same monopoly distortions on the production side (hence we do not consider a production subsidy in our policy analysis either). Table 7 summarizes these results.

Table 7: Social Planner's Optimum (in Percentages)

\begin{tabular}{ccccccccccc}
\hline \hline$\tau_{a}^{S P}$ & $\tau_{b}^{e, S P}$ & $\tau_{b}^{d, S P}$ & $L_{p}^{S P}$ & $L_{b}^{S P}$ & $L_{u}^{S P}$ & $L_{e}^{S P}$ & $L_{a}^{S P}$ & $\alpha$ & $g$ & $\beta$ \\
\hline 19.1 & 5.1 & 0.2 & 82.9 & 5.6 & 0.5 & 3.7 & 7.3 & 31.1 & 1.80 & 103.6 \\
\hline \hline
\end{tabular}

One striking feature of the solution to the social planner's problem under both scenarios is that the fraction of labor devoted to research activities is not substantially greater than in the decentralized equilibrium. In particular, the total labor allocated to production activities was $85.6 \%$ in the decentralized economy, while it is $82.9 \%$ when set by the social planner. Hence, there is a slight overinvestment in production labor relative to research labor, but this misallocation is quantitatively quite small.

Indeed, the dominant misallocation here is not that between production and research, as is common in this class of models, but among the various types of research activities, in this case, applied and basic innovation. In the decentralized economy, only $1.05 \%$ of the total labor force is devoted to basic research, whereas in the social planner's economy, this number rises to $6.1 \%$. In other words, the social planner devotes $36 \%$ of research labor to basic research, whereas this fraction was only $7 \%$ in the decentralized economy. This happens on both the intensive and the extensive margins of basic research. In fact, the planner finds it optimal to employ nearly all private research labs, regardless of their fixed cost draw.

Another interesting and important finding is that in the case of applied innovation, there is actually an overinvestment in the baseline economy. The applied research labor utilization (including entrants) is $13.6 \%$ in the decentralized case. This figure drops to $11 \%$ in the social planner's solution. This is in spite of the fact that the fraction of hot product lines rises from $7 \%$ to $31 \%$, meaning the average 
step size of an applied innovation rises by almost a third.

The net result of the above changes is that growth rises from $1.34 \%$ to $1.8 \%$. Overall, the decentralized economy's welfare corresponds to a decrease of $3.6 \%$ in consumption-equivalent terms from the social planner's optimum. The following policy experiments will try to bridge this gap.

\section{Policy Analysis}

In this section, we analyze the impact of different types of research subsidies when public basic research features delayed applicability (the "Ivory Tower" effect). ${ }^{14}$ Given our distinction between basic and applied research, it seems natural to propose different subsidy policies for different types of research spending. However, this could potentially generate a moral hazard problem, since firms would have an incentive to misreport the type of research they undertake, which is very difficult for a policymaker to verify. However, it is still useful to consider this hypothetical case to form a benchmark.

This section is organized as follows: Section 4.1 starts with this hypothetical case, Section 4.2 considers a uniform research subsidy as in the real world, and finally Section 4.3 combines both uniform subsidy and public research funding using feasible policy tools.

\subsection{Type-Dependent Research Subsidy}

Assume first that the policymaker can distinguish between different types of research efforts and accordingly provide differentiated subsidy rates. Let $\psi_{a}$ and $\psi_{b}$ denote the applied research and basic research subsidy rates, respectively. The share of GDP allocated to public research $(R / Z)$ is kept constant by the policymaker. Note that an increase in the subsidy rate $\left(\psi_{a}\right.$ or $\left.\psi_{b}\right)$ reduces research costs for the firm and leads to an increase in research effort as a result. The following table reports the optimal subsidy rates and resulting equilibrium variables.

Table 8: Type-Dependent Research Subsidy (in percentages)

\begin{tabular}{cccccccccccccc}
\hline \hline$\psi_{a}^{T D}$ & $\psi_{b}^{T D}$ & $R / Z$ & $\tau_{a}^{T D}$ & $\tau_{b}^{e, T D}$ & $\tau_{b}^{d, T D}$ & $L_{p}^{T D}$ & $L_{b}^{T D}$ & $L_{u}^{T D}$ & $L_{e}^{T D}$ & $L_{a}^{T D}$ & $\alpha^{T D}$ & $g^{T D}$ & $\beta^{T D}$ \\
\hline 14 & 50 & 0.5 & 19.3 & 4.50 & 0.38 & 83.1 & 5.3 & 0.50 & 3.7 & 7.5 & 29.6 & 1.75 & 103.0 \\
\hline \hline
\end{tabular}

Since the underinvestment is mainly in basic research, the optimal type-dependent subsidy dictates a much larger subsidy rate for it, namely, $\psi_{b}=50 \%$ and $\psi_{a}=14 \%$. Here, the major component of policy is a fivefold increase in the subsidy rate for basic research, whereas the subsidy rate on applied innovation remains roughly the same.

The large value for the basic research subsidy is straightforward to understand. There are spillovers associated with basic innovation that are not internalized by firms. By subsidizing this type of innovation, we can mitigate this effect. This policy can almost achieve the level of welfare seen in the social planner's case in Table 7 (103.6\% vs 103.0\%).

\footnotetext{
${ }^{14}$ In Section 5, we will go to the other extreme and consider optimal policies when public basic research also has immediate applicability.
} 
As discussed above, this policy is hard to implement in the real world due to the moral hazard problem. Therefore, we focus on a policy providing a uniform subsidy across the economy.

\subsection{Uniform Private Research Subsidy}

With this policy, the government subsidizes a fraction $\psi$ of each firm's total research investment, keeping the share of funds allocated to academic research constant. Note that such a policy subsidizes not only basic research but also applied research similar to the current R\&D subsidy policy in the U.S. and around the world. Table 9 summarizes the results of the optimal uniform subsidy rate.

Table 9: Uniform Research Subsidy (in Percentages)

\begin{tabular}{ccccccccccccc}
\hline \hline$\psi^{U P}$ & $R / Z$ & $\tau_{a}^{U P}$ & $\tau_{b}^{e, U P}$ & $\tau_{b}^{d, U P}$ & $L_{p}^{U P}$ & $L_{b}^{U P}$ & $L_{u}^{U P}$ & $L_{e}^{U P}$ & $L_{a}^{U P}$ & $\alpha^{U P}$ & $g^{U P}$ & $\beta^{U P}$ \\
\hline 31 & 0.5 & 25.4 & 1.52 & 0.26 & 81.8 & 1.54 & 0.49 & 5.41 & 10.8 & 13.2 & 1.70 & 100.8 \\
\hline \hline
\end{tabular}

Our analysis of the baseline economy and the planner's economy documented a slight underinvestment in research overall and a large misallocation between the different types of research. A uniform subsidy is therefore ill suited to address these issues as it cannot directly affect the allocation between research types, and any attempt to subsidize basic research will only worsen the overinvestment in applied research. Although the optimal type-dependent basic subsidy is 50\%, the optimal uniform subsidy is only $31 \%$, due to cross-subsidization of applied research whose optimal level was $14 \%$.

Under this policy, we are allocating a larger fraction of the labor force to research relative to the social planner's economy. Overall, the researcher's share goes up to $18 \%$ from $14 \%$. As a result, we have too few workers devoted to production of the consumption good $(81.8 \%)$ relative to the social planner's allocation (82.9\%), which reduces the initial consumption of the baseline economy. Even though we have more labor working for research, the economy grows at a lower rate $(1.7 \%)$ than the social planner's (1.8\%). This interesting result emerges due to the misallocation of researchers between basic and applied innovation. The welfare gain from this policy is 0.8 percentage points, which is only $27 \%(=0.8 / 3.0)$ as large as that for the type-dependent policy.

Although the underinvestment in basic research is sizable, the uniform policy partially makes up for this at the cost of worsening the overinvestment in applied research. The main lesson to be drawn from this is that when considering a uniform research subsidy, one should take into account the negative welfare effects associated with oversubsidization of applied research. Finding a feasible method to differentiate basic and applied research is essential for better innovation policies.

\subsection{Optimal Feasible Policy: Uniform Subsidy and Academic Budget}

Our final policy experiment combines optimal uniform subsidy rate with the optimal public funding level for academic research as a fraction of GDP $(R / Z)$. We will allow both the uniform subsidy rate and the academic funding rate to be chosen by the policymaker. The advantage of considering both types of policies is to introduce more freedom to control the incentives for both types of research in a largely separate way. In particular, $\psi$ and $R / Z$ are going to be the choice variables in this exercise. 
The following table contains the results of this experiment

Table 10: Optimal Academic And Uniform Policy (in Percentages)

\begin{tabular}{ccccccccccccc}
\hline \hline$\psi$ & $R / Z$ & $\tau_{a}$ & $\tau_{b}^{e}$ & $\tau_{b}^{d}$ & $L_{p}$ & $L_{b}$ & $L_{u}$ & $L_{e}$ & $L_{a}$ & $\alpha$ & $g$ & $\beta$ \\
\hline 31 & 0.7 & 25.4 & 1.5 & 0.6 & 81.6 & 1.5 & 0.7 & 5.4 & 10.8 & 15.5 & 1.72 & 100.8 \\
\hline \hline
\end{tabular}

When considered jointly, the optimal uniform R\&D subsidy is $31 \%$ and the optimal fraction of GDP allocated for public research is $0.7 \%$. These figures are respectively only $10 \%$ and $0.5 \%$ in France (and in the benchmark case). Such a policy increases the fraction of hot product lines from $6.9 \%$ to $15.5 \%$. However, one should also note that this policy makes a rather limited contribution to growth and welfare due to the Ivory Tower nature of academic research. The growth rate increases 0.02 percentage points relative to the optimal uniform policy of Table 9. These improvements are mitigated by the delayed applicability of the academic research which is partly a consequence of missing property rights for academic innovations. Policies that speed up this delay could potentially have important contributions to growth and welfare, which is our focus in the next section.

\section{Public Basic Research with Immediate Applicability}

So far we have assumed that public innovations have a delayed effect on productivity in a particular product line. A basic innovation by the public sector impacts the economy only after a private firm utilizes it with its own applied innovation, which happens every 5 years on average. This generates some disembodied basic innovations in equilibrium. However, one can argue that some policies enhance the applicability of academic innovations by allowing universities to retain ownership of inventions made using federal funds or by building joint ventures with the private sector. This is an interesting policy question, which we can analyze in our setting. We will study this appropriability problem by considering a scenario where basic academic research is immediately turned into an innovation. It should be noted that academic research, as we have all experienced, has a much wider set of objectives than purely generating consumer products (such as education, to say the least). Although we believe that they are also very important, our analysis will abstract from those considerations and will mainly focus on productivity consequences.

Table 11 considers this new environment where public basic research functions very much like private basic research in terms of its applicability. Therefore, in Panel A we again report the equilibrium values of the status quo economy as in Table 6 . When academic research has immediate applicability, equilibrium welfare improves by 0.4 percentage point and becomes 100.4 . In Table 11, we renormalize this new benchmark to $100.0 \%$ (dividing it by 100.4) and the following panels report their welfare numbers relative to this new benchmark.

Panel B solves for the social planner problem. This time the welfare gap between the two is bigger $(=4.5 \%)$. This is due to the fact that the planner wants to allocate $2.3 \%$ of the workforce into public basic research whereas the current policies allocate only $0.5 \%$ of the workforce. In addition, private 
firms invest too much into applied research $\left(L_{a}=8.9 \%\right.$ compared to $\left.7 \%\right)$ and too little into basic research $\left(L_{b}=0.5 \%\right.$ compared to $\left.4.6 \%\right)$.

Table 11: Policy Experiments with Immediate Applicability of Public Basic Research (in percentages)

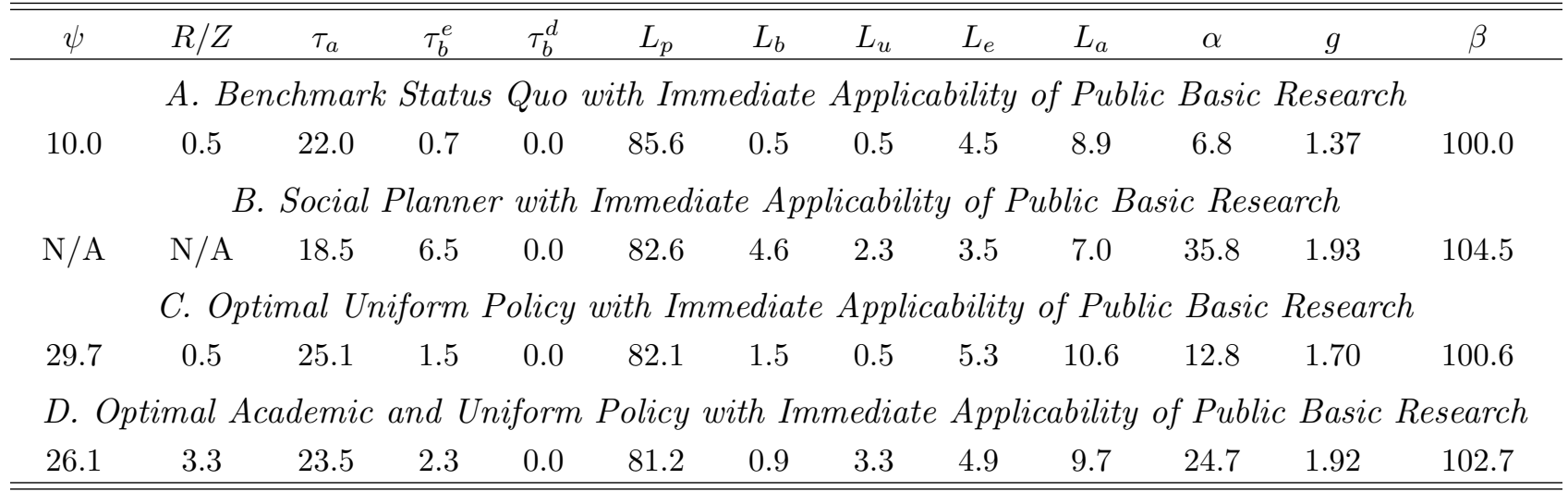

Panel $\mathrm{C}$ focuses on the optimal uniform $\mathrm{R} \& \mathrm{D}$ subsidy and the results are very similar to Table 9. Equilibrium welfare improves slightly by 0.6 percentage points. The contribution of R\&D subsidy is yet again mitigated by the fact that uniform subsidy increases the applied research investment to $L_{a}=10.6$, furthering the overinvestment.

Panel D studies the optimal uniform subsidy together with the optimal fraction of GDP allocated for academic research. Under this policy, the optimal rates are $26.1 \%$ and $3.3 \%$, respectively. This policy combination increases the growth rate to $1.92 \%$ and achieves the highest welfare result among all policies considered. By using the level of academic funding to reach the proper share of researchers, the policymaker is able to lower the uniform subsidy, thus reducing needless cross-subsidization of applied research. Under the current policy $81.2 \%$ of the labor force is allocated to production, a significant reduction over that of the baseline case in Panel A. This time around, the composition of workers between applied and basic research is closer to the social optimum. The resulting welfare is $2.7 \%$ higher than the status quo economy and closes $60 \%(=2.7 / 4.5)$ of the gap between the social planner and the decentralized economy.

To summarize our findings, we first considered the most widely discussed policy, which is a uniform subsidy. Using this tool optimally yielded limited improvement in welfare due to oversubsidization of applied research, as the policy could not distinguish between research types with different spillover and productivity implications. Considering a policy combination that governs both private and academic research in which the researchers can appropriate the returns to their innovations could generate a significant improvement. The first main conclusion to be drawn for innovation policy is the importance of recognizing different types of research and the impact of policies on them. The second is that it is important to take into account both the direct and indirect effects of academic research on productivity growth and the role of researchers' appropriability of their outcomes when considering growth and innovation policies. 


\section{Conclusion}

In this paper, we distinguished between basic and applied research and identified spillovers associated with each. Our quantitative analysis highlighted the importance of this distinction. Indeed, in the competitive equilibrium, applied research is overinvested in and basic research is underinvested in. As a result, imposing a uniform research subsidy does not generate the expected welfare improvement due to inefficient cross-subsidization of applied research. The key message of our paper is therefore that standard R\&D policies can accentuate the dynamic misallocation in the economy.

Interestingly, our policy experiment relative to the uniform research subsidy closely resembles a recent reform of French R\&D policy. In 2008 the French government introduced a $30 \%$ tax credit for all R\&D related expenditures of firms. While the new system represented a significant subsidy to private R\&D, with an annual budget of 5 billion Euros, its effectiveness in boosting innovation has been widely criticized [Larousserie (2015)].

Our findings can account for the limited impact of such policies, and point to the need for targeting basic research more directly. Our paper took a first step in trying to quantify the inefficiencies regarding different types of research and innovation efforts. There are still important open questions awaiting further study. In particular, the effect of university licensing and collaboration opportunities between universities and the private sector are two examples. We hope further structural work will be undertaken to enhance our understanding of the aforementioned issues, which can then guide the relevant innovation policies.

\section{References}

Acemoglu, D., U. Akcigit, N. Bloom, and W. R. Kerr (2013): "Innovation, Reallocation and Growth," National Bureau of Economic Research WP 18993.

Acemoglu, D., U. Akcigit, D. Hanley, and W. Kerr (2016): "Transition to Clean Technology," Journal of Political Economy, 124(1), 52-104.

Aghion, P., U. Akcigit, And P. Howitt (2014): "What Do We Learn From Schumpeterian Growth Theory?," in Handbook of Economic Growth, ed. by P. Aghion, and S. N. Durlauf, vol. 2 of Handbook of Economic Growth, pp. 515 - 563. Elsevier.

Aghion, P., M. Dewatripont, and J. C. Stein (2008): "Academic Freedom, Private-sector Focus, and the Process of Innovation," RAND Journal of Economics, 39(3), 617-635.

Aghion, P., And P. Howitt (1996): "Research and Development in the Growth Process," Journal of Economic Growth, 1(1), pp. 49-73.

\section{(2009): The Economics of Growth. MIT Press.}

Akcigit, U., M. A. Celik, and J. Greenwood (2016): "Buy, Keep, or Sell: Economic Growth and the Market for Ideas," Econometrica, 84(3), 943-984.

Akcigit, U., D. Hanley, and S. Stantcheva (2016): "Optimal Taxation and R\&D Policies," Center for Economic Policy Research Discussion Paper \#11682.

Akcigit, U., And W. R. KerR (2016): "Growth through Heterogeneous Innovations," Center for Economic Policy Research Discussion Paper \#11660. 
Ates, S. T., And F. Saffie (2014): "Fewer but Better: Sudden Stops, Firm Entry, and Financial Selection," PIER Working Paper \# 13-011.

Atkeson, A., And A. Burstein (2015): "Aggregate Implications of Innovation Policy," UCLA Working Paper.

Bloom, N. (2009): "The Impact of Uncertainty Shocks," Econometrica, 77(3), 623-685.

Bloom, N., M. Schankerman, and J. Van Reenen (2013): "Identifying Technology Spillovers and Product Market Rivalry," Econometrica, 81(4), 1347-1393.

Cozzi, G., And S. Galli (2009): "Science-based R\&D in Schumpeterian Growth," Scottish Journal of Political Economy, 56(4), 474-491.

(2014): "Sequential R\&D and Blocking Patents in the Dynamics of Growth," Journal of Economic Growth, 19(2), 183-219.

Cozzi, G., and G. Impullitti (2010): "Government Spending Composition, Technical Change, and Wage Inequality," Journal of the European Economic Association, 8(6), 1325-1358.

Dhont-Peltrault, E., and E. Pfister (2011): "R\&D Cooperation versus R\&D Subcontracting: Empirical Evidence from French Survey Data," Economics of Innovation and New Technology, 20(4), 309-341.

Foster, L., J. C. Haltiwanger, and C. J. Krizan (2001): "Aggregate Productivity Growth: Lessons from Microeconomic Evidence," in New Developments in Productivity Analysis, pp. 303372. University of Chicago Press.

Galasso, A., and M. Schankerman (2015): "Patents and Cumulative Innovation: Causal Evidence from the Courts," Quarterly Journal of Economics, 130(1), 317-369.

Garcia-Macia, D., C.-T. Hsieh, and P. J. Klenow (2015): "How Destructive is Innovation?," Stanford University Working Paper.

Garicano, L., C. Lelarge, and J. Van Reenen (2016): "Firm Size Distortions and the Productivity Distribution: Evidence from France," American Economic Review, forthcoming.

Gersbach, H., And M. T. Schneider (2015): "On the Global Supply of Basic Research," Journal of Monetary Economics, 75, 123 - 137.

Gersbach, H., M. T. Schneider, and O. Schneller (2013): "Basic Research, Openness, and Convergence," Journal of Economic Growth, 18(1), 33-68.

Griliches, Z. (1990): "Patent Statistics as Economic Indicators: A Survey," Journal of Economic Literature, 28(4), 1661-1707.

Howitt, P. (2000): The Economics of Science and the Future of Universities. Citeseer.

Impullitti, G. (2010): "International Competition and US R\&D Subsidies: A Quantitative Welfare Analysis," International Economic Review, 51(4), 1127-1158.

Joint Economic Committee (JEC) (2010): "The 2010 Joint Economic Report," Washington, DC: Government Printing Office.

(2016): "The 2016 Joint Economic Report," Washington, DC: Government Printing Office.

Klette, T. J., And S. S. Kortum (2004): "Innovating Firms and Aggregate Innovation," Journal of Political Economy, 112(5), 986-1018.

Kortum, S. S. (1992): "Inventions, R\&D and Industry Growth," Ph.D. Dissertation, Yale Univ., New Haven, CT. 
(1993): "Equilibrium R\&D and the Patent-R\&D Ratio: US Evidence," American Economic Review, 83(2), 450-457.

Larousserie, D. (2015): "Crédit Impôt Recherche : Un Rapport Passé sous Silence," Le Monde. Accessed online at: http://www.lemonde.fr. October 6, 2015.

Lentz, R., And D. T. Mortensen (2008): "An Empirical Model of Growth through Product Innovation," Econometrica, 76(6), 1317-1373.

$4-19$.

(2016): "Optimal Growth through Product Innovation," Review of Economic Dynamics, 19,

Mansfield, E. (1995): "Academic Research Underlying Industrial Innovations: Sources, Characteristics, and Financing," Review of Economics and Statistics, 77(1), 55-65.

Morales, M. F. (2004): "Research Policy and Endogenous Growth," Spanish Economic Review, 6(3), 179-209.

Mowery, D. C., R. R. Nelson, B. Sampat, and A. Ziedonis (2004): Ivory Tower and Industrial Innovation: University-Industry Technology Transfer before and after the Bayh-Dole Act in the United States. Stanford University Press.

Nelder, J. A., And R. Mead (1965): "A Simplex Method for Function Minimization," Computer Journal, 7(4), 308-313.

Nelson, R. R. (1959): "The Simple Economics of Basic Research," Journal of Political Economy, $67(3), 297-306$.

Pakes, A., And Z. Griliches (1984): "Estimating Distributed Lags in Short Panels with an Application to the Specification of Depreciation Patterns and Capital Stock Constructs," Review of Economic Studies, 51(2), 243-262.

Peters, M. (2015): "Heterogeneous Mark-ups and Endogenous Misallocation," Yale Working Paper.

Powell, M. J. (1970): "A Hybrid Method for Nonlinear Equations," Numerical Methods for Nonlinear Algebraic Equations, 7, 87-114.

Rosenberg, N., and R. R. Nelson (1994): "American Universities and Technical Advance in Industry," Research Policy, 23(3), 323-348.

Zangwill, W. I., and C. Garcia (1981): Pathways to Solutions, Fixed Points, and Equilibria. Prentice-Hall Englewood Cliffs, New Jersey. 


\section{Appendix}

\section{A Theoretical Proofs}

As the downstream production technology is unchanged in the generalized model and we continue to impose symmetry across the industries. This implies that

$$
P_{i}=P=\frac{1}{M} \quad \text { and } \quad Y_{i}=Y=Z
$$

Henceforth, we can drop the industry index $i$. The perfectly competitive firm that produces midstream good $Y_{i}$ takes equilibrium prices $P$ and $p_{j}$ as given while maximizing its profit

$$
\max _{y_{j}}\left\{P\left[\int_{0}^{1} y_{j}^{\frac{\varepsilon-1}{\varepsilon}} d j\right]^{\frac{\varepsilon}{\varepsilon-1}}-\int_{0}^{1} p_{j} y_{j} d j\right\} .
$$

This maximization leads to the following inverse demand for upstream good $j$

$$
p_{j}=P\left(\frac{Y}{y_{j}}\right)^{\frac{1}{\varepsilon}} .
$$

Monopolist in product line $j, j$ has productivity $q_{j}$. The firm takes the demand function for its product as given and solves the following maximization problem

$$
\pi_{j}=\max _{y_{j}}\left\{P Y^{\frac{1}{\varepsilon}} y_{j}^{\frac{\varepsilon-1}{\varepsilon}}-\frac{w}{q_{j}} y_{j}\right\}
$$

This delivers the following optimal quantity

$$
y_{j}=\left[\frac{1}{M}\left(\frac{\varepsilon-1}{\varepsilon}\right)\left(\frac{q_{j}}{w}\right)\right]^{\varepsilon} Z
$$

Plugging this into the production function for midstream goods, we find a relationship between wage $w$ and aggregated productivity $\bar{q} \equiv\left(\int q_{j}^{\varepsilon-1} d j\right)^{\frac{1}{\varepsilon-1}}$

$$
w=\frac{1}{M}\left(\frac{\varepsilon-1}{\varepsilon}\right) \bar{q}
$$

With this, we can greatly simplify the expression of the firm's quantity and price choices as a function of its normalized productivity $\hat{q}_{j}=q_{j} / \bar{q}$

$$
y_{j}=\hat{q}_{j}^{\varepsilon} Z \quad \text { and } \quad p_{j}=\frac{1}{M \hat{q}_{j}}
$$

Denote variables normalized by $Z / M$ with a " ". Then the normalized profit and labor are given by

$$
\tilde{\pi}_{j}=\frac{\hat{q}_{j}^{\varepsilon-1}}{\varepsilon} \quad \text { and } \quad l_{j}=\frac{\hat{q}_{j}^{\varepsilon-1}}{\tilde{w}}\left(\frac{\varepsilon-1}{\varepsilon}\right) .
$$

where $\tilde{w}$ is the normalized wage. Note that by construction $\int \hat{q}_{j}^{\varepsilon-1} d j=1$. As a result, we integrate 25 over $j$ to find profit share and production labor share as

$$
\frac{M \int_{0}^{1} \pi_{j} d j}{Z}=\frac{1}{\varepsilon} \quad \text { and } \quad \frac{w L_{P}}{Z}=\frac{\varepsilon-1}{\varepsilon} .
$$

Finally, we combine 24 and 26 to find the final output as a function of aggregate productivity $\bar{q}$ and total production labor $L_{P}$ :

$$
Z=\bar{q} L_{P} / M \text {. }
$$


Proof of Lemma 1 Let $\mathcal{F}_{H}(\cdot, t)$ and $\mathcal{F}_{C}(\cdot, t)$ be the aggregate product cumulative measures by type (hot or hold) at time $t$. For a small time step $\Delta$, hot distribution $\mathcal{F}_{H}(\cdot, t)$ will satisfy

$$
\begin{aligned}
\mathcal{F}_{H}(\hat{q}, t+\Delta)= & \mathcal{F}_{H}(\hat{q} /(1+\Delta g), t)-\Delta \tau\left[\mathcal{F}_{H}(\hat{q} /(1+\Delta g), t)-\mathcal{F}_{H}(\hat{q} /(1+\Delta g)-\eta, t)\right] \\
& +\Delta \tau_{b}^{e} \mathcal{F}_{C}(\hat{q} /(1+\Delta g)-\eta, t)-\Delta \zeta \mathcal{F}_{H}(\hat{q} /(1+\Delta g), t)+\Delta \tau_{b}^{d} \mathcal{F}_{C}(\hat{q} /(1+\Delta g), t)
\end{aligned}
$$

Similarly, the cold distribution $\mathcal{F}_{C}(\cdot, t)$ will satisfy

$$
\begin{aligned}
\mathcal{F}_{C}(\hat{q}, t+\Delta)= & \mathcal{F}_{C}(\hat{q} /(1+\Delta g), t)-\Delta \tau_{a}\left[\mathcal{F}_{C}(\hat{q} /(1+\Delta g), t)-\mathcal{F}_{C}(\hat{q} /(1+\Delta g)-\lambda, t)\right] \\
& -\Delta \tau_{b} \mathcal{F}_{C}(\hat{q} /(1+\Delta g), t)+\Delta \zeta \mathcal{F}_{H}(\hat{q} /(1+\Delta g), t)
\end{aligned}
$$

Finally, for $i \in\{H, C\}$, calculating

$$
\dot{\mathcal{F}}_{i}(\hat{q})=\frac{\mathcal{F}_{i}(\hat{q}, t+\Delta)-\mathcal{F}_{i}(\hat{q}, t)}{\Delta}
$$

and taking the limit as $\Delta \rightarrow 0$ yields the desired flow equations. Note that for this we use

$$
\frac{\mathcal{F}_{i}(\hat{q} /(1+\Delta g), t)-\mathcal{F}_{i}(\hat{q}, t)}{\Delta}=-g \hat{q}\left[\partial \mathcal{F}_{i}(\hat{q}) / \partial \hat{q}\right]
$$

Proof of Proposition 1. Let $\mathcal{F}(\cdot, t)$ be the distribution over $q$ at time $t$. Similarly, let $\mathcal{F}_{H}(\cdot, t)$ and $\mathcal{F}_{C}(\cdot, t)$ be the product type (hot/cold) conditional distributions. Thus, we will have $\mathcal{F}(q, t)=\alpha \mathcal{F}_{H}(q, t)+(1-\alpha) \mathcal{F}_{C}(q, t)$. The evolution of the aggregated productivity index $\bar{q}$ is then given by

$$
\begin{aligned}
\bar{q}^{\varepsilon-1}(t+\Delta t)= & \int_{0}^{\infty} q^{\varepsilon-1} d \mathcal{F}(q, t+\Delta t) \\
= & \alpha \int_{0}^{\infty} q^{\varepsilon-1} d \mathcal{F}_{H}(q, t+\Delta t)+(1-\alpha) \int_{0}^{\infty} q^{\varepsilon-1} d \mathcal{F}_{C}(q, t+\Delta t) \\
= & \alpha \int_{0}^{\infty}\left[\Delta \tau(q+\eta \bar{q})^{\varepsilon-1}+(1-\Delta \tau) q^{\varepsilon-1}\right] d \mathcal{F}_{H}(q, t) \\
& +(1-\alpha) \int_{0}^{\infty}\left[\Delta \tau_{a}(q+\lambda \bar{q})^{\varepsilon-1}+\Delta \tau_{b}^{e}(q+\eta \bar{q})^{\varepsilon-1}+(1-\Delta \tau) q^{\varepsilon-1}\right] d \mathcal{F}_{C}(q, t)
\end{aligned}
$$

Thus the differential is

$$
\begin{aligned}
\frac{\bar{q}^{\varepsilon-1}(t+\Delta t)-\bar{q}^{\varepsilon-1}(t)}{\Delta}= & \alpha \int_{0}^{\infty} \tau\left[(q+\eta \bar{q})^{\varepsilon-1}-q^{\varepsilon-1}\right] d \mathcal{F}_{H}(q, t) \\
& +(1-\alpha) \int_{0}^{\infty}\left(\tau_{a}\left[(q+\lambda)^{\varepsilon-1}-q^{\varepsilon-1}\right]+\tau_{b}^{e}\left[(q+\eta)^{\varepsilon-1}-q^{\varepsilon-1}\right]\right) d \mathcal{F}_{C}(q, t)
\end{aligned}
$$

and the normalized differential is

$$
\begin{aligned}
\frac{\bar{q}^{\varepsilon-1}(t+\Delta t)-\bar{q}^{\varepsilon-1}(t)}{\Delta \bar{q}^{\varepsilon-1}(t)}= & \alpha \int_{0}^{\infty} \tau\left[(\hat{q}+\eta)^{\varepsilon-1}-\hat{q}^{\varepsilon-1}\right] d \mathcal{F}_{H}(\hat{q}, t) \\
& +(1-\alpha) \int_{0}^{\infty}\left(\tau_{a}\left[(\hat{q}+\lambda)^{\varepsilon-1}-\hat{q}^{\varepsilon-1}\right]+\tau_{b}^{e}\left[(\hat{q}+\eta)^{\varepsilon-1}-\hat{q}^{\varepsilon-1}\right]\right) d \mathcal{F}_{C}(\hat{q}, t)
\end{aligned}
$$

Finally, the growth can be expressed compactly as

$$
g=\frac{\alpha \tau \mathbb{E}_{\hat{q}}^{H}\left[(\hat{q}+\eta)^{\varepsilon-1}-\hat{q}^{\varepsilon-1}\right]+(1-\alpha)\left(\tau_{a} \mathbb{E}_{\hat{q}}^{C}\left[(\hat{q}+\lambda)^{\varepsilon-1}-\hat{q}^{\varepsilon-1}\right]+\tau_{b}^{e} \mathbb{E}_{\hat{q}}^{C}\left[(\hat{q}+\eta)^{\varepsilon-1}-\hat{q}^{\varepsilon-1}\right]\right)}{\varepsilon-1}
$$


This can also be rearranged into

$$
g=\frac{\tau_{a}\left(\alpha \mathbb{E}_{\hat{q}}^{H}\left[(\hat{q}+\eta)^{\varepsilon-1}-\hat{q}^{\varepsilon-1}\right]+(1-\alpha) \mathbb{E}_{\hat{q}}^{C}\left[(\hat{q}+\lambda)^{\varepsilon-1}-\hat{q}^{\varepsilon-1}\right]\right)+\tau_{b}^{e} \mathbb{E}_{\hat{q}}\left[(\hat{q}+\eta)^{\varepsilon-1}-\hat{q}^{\varepsilon-1}\right]}{\varepsilon-1}
$$

Proof of Proposition 2. The firm value, in general form, can be expressed as

$$
\begin{aligned}
& r \mathcal{V}_{t}(\hat{\mathbf{q}}, m)-\dot{\mathcal{V}}_{t}(\hat{\mathbf{q}}, m) \\
& =\max _{a, b}\left\{\begin{array}{c}
\left.\sum_{\hat{q} \in \hat{\mathbf{q}}} \frac{1}{\varepsilon} \hat{q}^{\epsilon-1} \frac{Z_{t}}{M}-n w_{t}\left[h_{a}(a)+h_{b}(b)+\mathbf{1}_{(b>0)} \phi\right]\right] \\
+n a\left[\alpha \mathbb{E}_{\hat{q}}^{H} \mathcal{V}_{t}(\hat{\mathbf{q}} \cup\{\hat{q}+\eta\}, m)+(1-\alpha) \mathbb{E}_{\hat{q}}^{C} \mathcal{V}_{t}(\hat{\mathbf{q}} \cup\{\hat{q}+\lambda\}, m)-\mathcal{V}_{t}(\hat{\mathbf{q}}, m)\right] \\
+n b\left(1+\rho_{m}\right)\left[\mathcal{V}_{t}(\hat{\mathbf{q}} \cup\{\hat{q}+\eta\}, m)-\mathcal{V}_{t}(\hat{\mathbf{q}}, m)\right] \\
+\sum_{\hat{q} \in \hat{\mathbf{q}}} \tau\left[\sum_{\hat{q} \in \hat{\mathbf{q}}}\left[\mathcal{V}_{t}(\hat{\mathbf{q}} \backslash\{\hat{q}\}, m)-\mathcal{V}_{t}(\hat{\mathbf{q}}, m)\right]\right] \\
+x \frac{m}{M}\left[\alpha \mathbb{E}_{\hat{q}}^{H} \mathcal{V}_{t}(\hat{\mathbf{q}} \cup\{\hat{q}+\eta\}, m)+(1-\alpha) \mathbb{E}_{\hat{q}}^{C} \mathcal{V}_{t}(\hat{\mathbf{q}} \cup\{\hat{q}+\lambda\}, m)-p_{m}^{\prime}-\mathcal{V}_{t}(\hat{\mathbf{q}}, m)\right] \\
+x\left(1-\frac{m}{M}\right)\left[\alpha \mathbb{E}_{\hat{q}}^{H} \mathcal{V}_{t}(\hat{\mathbf{q}} \cup\{\hat{q}+\eta\}, m+1)+(1-\alpha) \mathbb{E}_{\hat{q}}^{C} \mathcal{V}_{t}(\hat{\mathbf{q}} \cup\{\hat{q}+\lambda\}, m+1)-p_{m}-\mathcal{V}_{t}(\hat{\mathbf{q}}, m)\right] \\
+n \kappa\left[\mathbb{E}_{\hat{q}} \mathcal{V}_{t}(\hat{\mathbf{q}} \cup\{\hat{q}\}, m)-\mathcal{P}-\mathcal{V}_{t}(\hat{\mathbf{q}}, m)\right] \\
+\kappa\left[n \mathcal{P}-\mathcal{V}_{t}(\hat{\mathbf{q}}, m)\right]
\end{array}\right\} .
\end{aligned}
$$

Now, conjecture $\mathcal{V}_{t}(\hat{\mathbf{q}})=\frac{Z_{t}}{M}\left[\sum_{\hat{q} \in \hat{\mathbf{q}}} V\left(\hat{q}_{t}\right)+n V_{m}\right]$. When we substitute the conjecture into the the above expression and using the prices

$$
\begin{aligned}
& p_{m}=V_{m+1}+\mathbb{E}_{\hat{q}, s} V\left(\hat{q}_{t+\Delta t}+\hat{s}\right) \\
& p_{m}^{\prime}=V_{m}+\mathbb{E}_{\hat{q}, s} V\left(\hat{q}_{t+\Delta t}+\hat{s}\right)
\end{aligned}
$$

we find

$$
(r-g) V_{m}=\max _{a, b}\left\{\begin{array}{c}
\left.-\tilde{w}\left[h_{a}(a)+h_{b}(b)+\mathbf{1}_{(b>0)} \phi\right]\right] \\
+a\left[\alpha V^{H}+(1-\alpha) V^{C}+V_{m}\right] \\
+b\left(1+\rho_{m}\right)\left[V^{H}+V_{m}\right] \\
+x\left(1-\frac{m}{M}\right)\left[V_{m+1}-V_{m}\right] \\
-\tau V_{m}+\kappa \mathbb{E}_{\hat{q}} V\left(\hat{q}_{t}\right)
\end{array}\right\}
$$

and

$$
V^{\prime}\left(\hat{q}_{t}\right) g \hat{q}+[\tau+\kappa+r-g] V\left(\hat{q}_{t}\right)=\frac{1}{\varepsilon} \hat{q}^{\epsilon-1} .
$$

Note that the last expression is a differential equation as a function of $\hat{q}$. Then

$$
V\left(\hat{q}_{t}\right)=\frac{\hat{q}_{t}^{\epsilon-1}}{\varepsilon[r+\tau+\kappa+g(\epsilon-2)]} .
$$

This completes the proof.

Derivation of Multi-industry Distribution $\Gamma_{m, n}$.

We assume that when a firm loses its last product in a particular industry, it maintains a foothold there, in the sense that it still receives buy-out offers and can still directly use basic research relevant to that industry. When a firm loses all of its products or receives a destructive shock, it ceases to exist. We wish to find the joint distribution over the number of industries a firm is in and how many product lines it owns. For notational convenience, let us denote the basic research flow from $m$-industry firms by $\hat{b}_{m}=\mathcal{B}\left(\phi_{m}\right) b_{m}$. Let us also denote the expansion rate of a firm into a new industry by $e_{m}$. Here the expansion rate comes purely from buy-out offers by entrants. So given a per firm buy-out offer rate of $x$, a firm in $m$ industries will expand at rate

$$
e_{m}=x\left(\frac{M-m}{M}\right)=\left(\frac{\varsigma E a_{e}}{F}\right)\left(\frac{M-m}{M}\right)
$$


Then the flow equation for firms in $m$ industries with $n$ products is

$$
\begin{aligned}
& \text { Outflow } \text { Inflow } \\
& {\left[\begin{array}{c}
a_{1}+\hat{b}_{1}+\tau+\kappa \\
+e_{1}+\kappa
\end{array}\right] \Gamma_{1,1}=a_{e}+2 \tau \Gamma_{1,2} } \\
& {\left[\begin{array}{c}
a_{m}+\hat{b}_{m}+\tau+\kappa \\
+e_{m}+\kappa
\end{array}\right] \Gamma_{m, 1}=2 \tau \Gamma_{m, 2}+e_{m-1} \Gamma_{m-1,1} \text { for } m \geq 2 } \\
& {\left[\begin{array}{c}
n\left(a_{m}+\hat{b}_{m}+\tau+\kappa\right) \\
+e_{m}+\kappa
\end{array}\right] \Gamma_{m, 2}=\left\{\begin{array}{c}
\left(a_{m}+\hat{b}_{m}\left(1-\rho_{m}\right)+\kappa\right) \Gamma_{m, n-1} \\
+3 \tau \Gamma_{m, n+1}+e_{m-1} \Gamma_{m-1, n}
\end{array}\right\} \text { for } m \geq 1 } \\
& {\left[\begin{array}{c}
n\left(a_{m}+\hat{b}_{m}+\tau+\kappa\right) \\
+e_{m}+\kappa
\end{array}\right] \Gamma_{m, n}=\left\{\begin{array}{c}
(n-1)\left(a_{m}+\hat{b}_{m}\left(1-\rho_{m}\right)+\kappa\right) \Gamma_{m, n-1} \\
+(n-2) \rho_{m} \hat{b}_{m} \Gamma_{m, n-2} \\
+(n+1) \tau \Gamma_{m, n+1}+e_{m-1} \Gamma_{m-1, n}
\end{array}\right\} \text { for } n \geq 3, m \geq 1 }
\end{aligned}
$$

where we use the convention $\Gamma_{m,-1}=\Gamma_{m, 0}=0$ and $e_{0}=0$. The first line equates the outflows from $(m=1, n=1)$ that happen once the firm loses its product at the rate $\tau+\kappa$, acquires a new product line at the rate $\kappa$, innovates a new good at the rate $a_{1}+\hat{b}_{1}$ on average or expands into a new industry at the rate $e_{1}$. On the other hand, inflow happens from outsiders at the rate $a_{e}$ and from the firms with 2 products that lose one of their products at the rate $2 \tau$. Similar reasoning applies to the subsequent lines.

Using values for the $\Gamma_{m, n}$ distribution gives us the mass of firms in a given $(m, n)$ state. The total mass of firms is then $F=\sum_{m=1}^{M} \sum_{n=1}^{\infty} \Gamma_{m, n}$. We ultimately want the mass of products in given industry state $m$. To get this we simply evaluate

$$
\mu_{m}=\sum_{n=1}^{\infty} n \cdot \Gamma_{m, n}
$$

\section{B Data Organization}

\section{Data Organization}

We first identify the ownership status of each firm in the economy and the head of the group with which the firm is affiliated. Indeed, our data source (LIFI) defines a group as a set of firms controlled, directly or indirectly, by the same entity (the head of the group). We rely on a formal definition of control, requiring that a firm holds directly or through cross-ownership at least $50 \%$ of the voting rights in another firm's general assembly. We do not expect this to be a major source of bias in our sample as most French firms are private and ownership concentration is strong even among listed firms. Firms that do not conform to this definition are classified as stand-alone firms.

We then match the ownership information to our balance-sheet data and to our survey on lines of business within firms. We drop firms that appear in the ownership data but for which we cannot find balance-sheet information. We also delete as outliers firm-year observations whose ROA falls outside a multiple of five of the interquartile range and firms that report 0 employment or which have negative sales. Based on our two sources of information we identify the main line of business from the balance sheets and the different segments of the firm from the survey on lines of business. For computational convenience we create a new firm-group identifier that allows us to aggregate at the same time business groups, business groups with multi-divisional firms, exclusively multi-divisional firms and true stand-alone firms. We then define four measures of multi-market activity. The first measure counts each market in which the firm-group is present either via its ownership links or its multi-divisional structure. The second measure counts each market in which the firm-group is present with at least 9 employees via its ownership links or its multi-divisional structure. The third measure counts each market in which the firm-group is present exclusively via its ownership links. The final measure counts each market in which the firm-group is present exclusively via its ownership links and excluding financial activities. 
We then define firm characteristics from balance-sheet data. There are three possible organizational types and comparison issues might arise. Taking the firm as the economic unit of interest has the advantage of simplicity since information is directly available in the balance sheets. However, this method has the disadvantage of not being comparable across organizational types. Indeed, most information for multi-divisional firms is aggregated across lines of segment, whereas firms belonging to business groups have market-specific information. Similar to existing studies by the Ministry of Research (Dhont-Peltrault and Pfister (2011)), we decided to aggregate the information to the economic unit at the highest level of control: the firm level for stand-alone and multi-divisional firms, and the business group level for firms affiliated through majority ownership. ${ }^{15}$

In a final step we match the firms' balance-sheet and patent information to information contained in the R\&D Survey. We focus on firms for which we have R\&D information. Again we aggregate at the highest level of control. As before, one has to be cautious in aggregating on the basis of variables that might be prone to double-counting. When constructing information on the basic R\&D intensity of a firm this is not the case as we are focusing exclusively on "internal" research expenditures. Therefore, if a member of the group contracts out research with another member of the group, then one will be counted as "external" research expenditures and the other one as "internal" expenditures. To correct for outliers in the dependent variable, we drop firm-year observations whose basic research intensity, conditional on positive basic research, falls outside a multiple of five of the interquartile range. In addition we exclude firm-year observations whose total $R \& D$ to sales ratio falls outside a multiple of five of the interquartile range. ${ }^{16}$

\section{Policy Environment}

It is useful to describe the policy environment in France during the period of our data. The share of GDP devoted R\&D expenditures in France was on average $2.2 \%$ between 2000 and 2006. Innovation policy during the sample period featured a mix of measures to support R\&D investment of firms through public financing. The main instrument to stimulate private innovation activity during that period consisted of approximately 2.5 billion euros of yearly subsidies allocated to firms either through ministries or government agencies such as OSEO-ANVAR. Note that our R\&D survey allows us to directly measure this form of public financing in our sample. Finally, the R\&D tax credit system was seen by the government as a secondary policy measure until a major reform in 2008 that increased the base and the rate of the the tax credit.

\section{Variable List}

All variables are organized and computed according to the method set out in the previous section. To summarize, we decided to aggregate the information to the economic unit at the highest level of control: the firm level for stand-alone and multi-divisional firms, and the business group level for firms affiliated through majority ownership. In the remainder of the document we will, for the sake of notational convenience, refer generically to firms.

- Basic Research Intensity: total basic research by firm $i$ in year $t$ divided by total applied research of firm $i$ in year $t$. The formulation of the survey questions related to the type of research undertaken is directly derived from the definitions provided by the Frascati Manual;

- \# of Industries: sum of all distinct SIC codes within firm $i$ in year $t$ irrespective of organizational form (business group or multi-divisional structure). Industries are successively defined at the 4-,3-,2- and 1-digit SIC levels;

- \# of Industries - Weighted Sum: weighted sum of all distinct bilateral 1-digit SIC links within firm $i$ in year $t$. Weights are computed on the basis of the empirical frequency of each bilateral SIC link in each year $t$;

- \# of Patent Classes Applied: sum of cumulated distinct patent-class applications within firm $i$ in year $t$. Cumulated patent-class applications are computed for the period leading from

\footnotetext{
${ }^{15}$ In addition to the economic rationale for constructing the data at the highest level of control there is also a legal argument. Indeed most public administrations and tribunals define the eligibility of firms for subsidy programs with respect to the business groups to which they belong.

${ }^{16}$ Alternatively, we exclude firm-year observations whose basic to applied R\&D ratio falls above the $99^{\text {th }}$ percentile of the distribution. The results are qualitatively similar.
} 
1993 to year $t$. Patent classes are successively defined at the 5,4,3,2 and 1-digit levels (EPO Classification);

- \# of Patent Classes Granted: sum of cumulated distinct patent-class grants within firm $i$ in year $t$. Cumulated patent-class grants are computed for the period leading from 1993 to year $t$. Patent classes are successively defined at the 5-,4-,3-,2- and 1-digit levels (EPO Classification);

- Financial Int.: binary indicator equal to 1 if firm $i$ in year $t$ is present in a financial industry, 0 otherwise;

- Foreign $H Q$ : binary indicator equal to 1 if the headquarters of firm $i$ in year $t$ are located outside France, 0 otherwise;

- Market Share: weighted average of total sales of firm $i$, year $t$ in industry $k$ divided by total industry sales in year $t$. Weights are computed on the basis of the industry share of employment within firm $i$ in year $t$;

- Outsourcing to Univ.: binary indicator equal to 1 if firm $i$ in year $t$ has outsourced R\&D to French universities, 0 otherwise;

- Profitability - ROA: weighted average of EBIDTA divided by total fixed assets of all subsidiaries within firm $i$ in year $t$. Weights are computed on the basis of the subsidiaries' share of employment within firm $i$ in year $t$;

- Profitability - ROS: weighted average of EBIDTA divided by total sales of all subsidiaries within firm $i$ in year $t$. Weights are computed on the basis of the subsidiaries' share of employment within firm $i$ in year $t$;

- Public RESD Funds: binary indicator equal to 1 if firm $i$ in year $t$ has received French public funds, 0 otherwise;

- Research Area: weighted average of the share of respectively biotech / software / environmental research in research expenditures in firm $i$ in year $t$. Weights are computed on the basis of the subsidiaries' share of total R\&D within firm $i$ in year $t$;

- Total Employment: total employment of firm $i$ in year $t$;

- IV - State Present in 1986: binary indicator equal to 1 if the French state had a non-zero equity stake in firm $i$ in 1986;

- $I V$ - SOE in 1986: binary indicator equal to 1 if the French state had a controlling equity stake in firm $i$ in 1986.

Table 12 provides the descriptive statistics of the key variables.

\section{Construction of Within-Industry Spillovers}

Figure 10 provides a graphical intuition for the computation of the citation information.

Patent A is granted in 1978. In 1981, when patent A is 3 years old, it receives citations from both patent $\mathrm{B}$ and patent $\mathrm{C}$, which was applied for in 1981. Patent B in the following 10 years was cited by patents $\mathrm{V}, \mathrm{W}$ and $\mathrm{X}$, whereas patent $\mathrm{C}$ was only cited by patents $\mathrm{Y}$ and $\mathrm{Z}$. The average citation of citing patents for patent $\mathrm{A}$ at age 3 is therefore 2.5. The timing of the computation implies that we need to be cautious with respect to possible truncation. We therefore compute our measure for patents between 1975 and 1985. This implies that, inclusive of the 10-years-forward lag, we can observe without truncation all our patents until the age of 10 .

Robustness Checks Table 13 provides robustness checks for the estimates on the cool-down rate of patents originating from basic and applied research. The top panel of the table measures Quality of Citing Patents computing the 5-years-forward citations of the citing patents and is measured for patents granted in the period 1975-1985. The bottom panel re-classifies university patents that were defined as private depositors. In both cases results are unchanged, with a citation difference between public and private patents that becomes statistically non-significant at year 8. Indeed, in France, most of the academic patents are accounted for in the "public" category. French universities generally manage their patents through public research institutions with which academics are typically affiliated, one example being the CNRS. 
Table 12: Descriptive Statistics

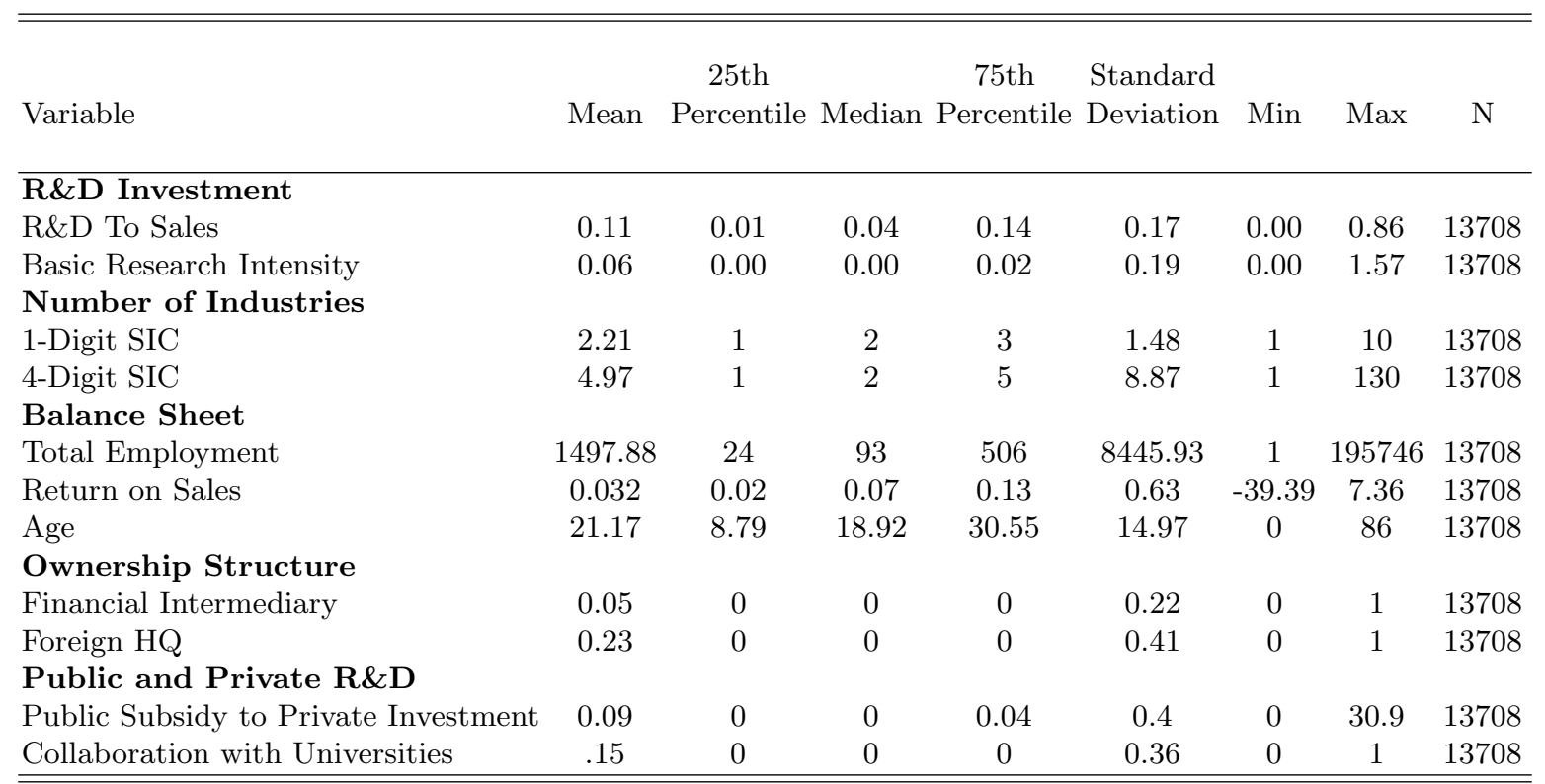

Note: Pooled data for the period 2000-2006. RED To Sales is defined as the ratio of total firm research and development

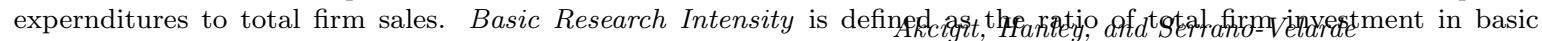
research to total firm investment in applied research. Number of Industries is the sum of all distinct SIC codes within the firm. Return on Sales is the ratio of earnings before interest, taxes, depreciation and amortization to total firm sales.

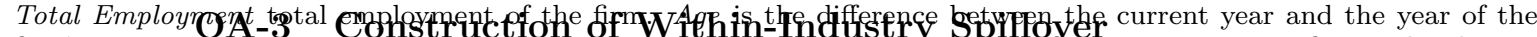
firm's incorporation. Financial Intermediary binary indicator equal to 1 if the firm is present in a financial industry,

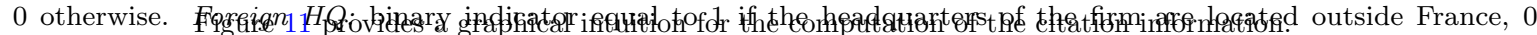
otherwise. Public Subsidy to Private Investment binary indicator equal to 1 if the firm has received French public funds for innovation expenditures, 0 otherwise. Collaboration with Universities binary indicator equal to 1 if the firm has received French public funds for innovation expenditures, 0 THE OCOOLING DOWN RATE

Figure 10: Computing the Cool-Down Rate

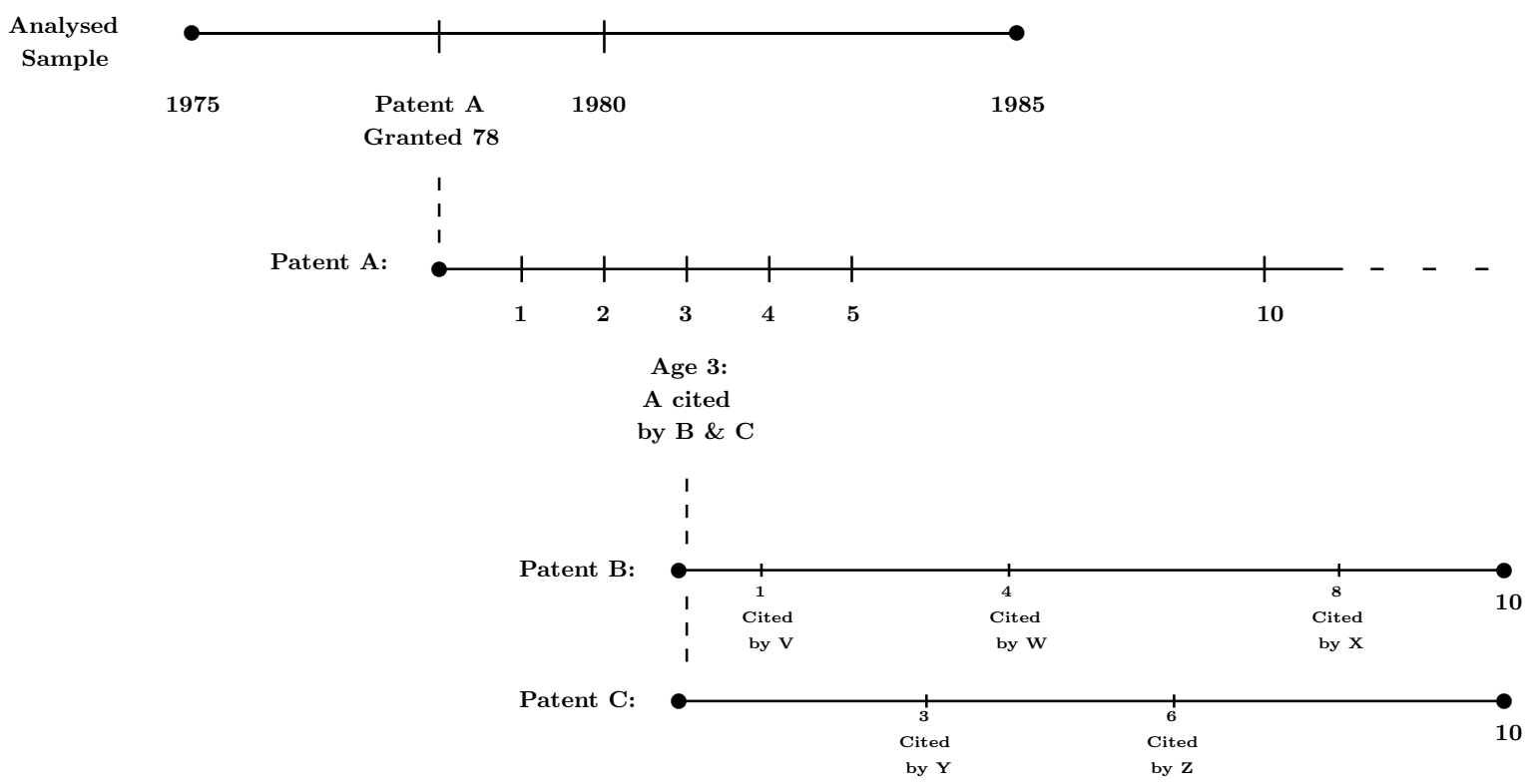

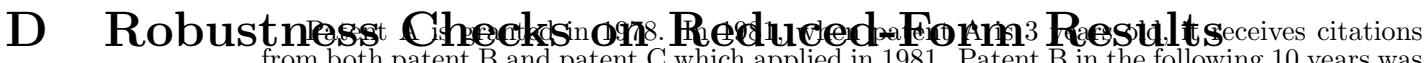
from both patent B and patent $C$ which applied in 1981 . Patent $B$ in the following 10 years was

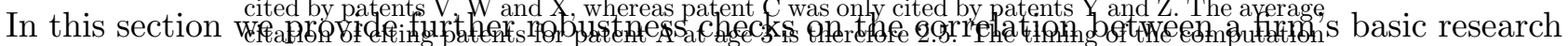

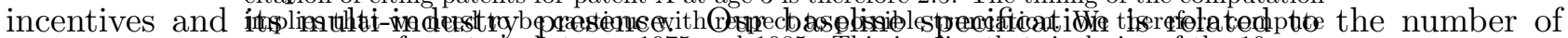
our measure for patents between 1975 and 1985 . This implies that, inclusive of the 10 year forward lag, we can observe without truncation all our patents until the age of 10 .

Robustness Checks Figure 12 provides robustness checks for the estimates on the cooling down rate of patents originating from basic and applied research. The left panel of the figure measures Average Citations of Citing Patents computing the 5 year forward citations of the citing patents and is measured for patents granted in the period 1975-1985. The right panel re-classifies university patents which were defined as private depositors. In both cases results 
Table 13: Citation Patterns for Public and Private Patents

\begin{tabular}{|c|c|c|c|c|c|c|c|c|c|c|}
\hline Age & 1 & 2 & 3 & 4 & 5 & 6 & 7 & 8 & 9 & 10 \\
\hline 5-Yr-Forward Citations & $\begin{array}{l}.15^{* *} \\
(0.07)\end{array}$ & $\begin{array}{l}.16^{* *} \\
(0.07)\end{array}$ & $\begin{array}{l}.28^{* * *} \\
(0.08)\end{array}$ & $\begin{array}{l}.16^{* *} \\
(0.06)\end{array}$ & $\begin{array}{l}.22^{* *} \\
(0.07)\end{array}$ & $\begin{array}{l}.15^{* *} \\
(0.07)\end{array}$ & $\begin{array}{l}.33^{* * *} \\
(0.11)\end{array}$ & $\begin{array}{c}.08 \\
(0.08)\end{array}$ & $\begin{array}{c}.18 \\
(0.11)\end{array}$ & $\begin{array}{c}.15 \\
(0.12)\end{array}$ \\
\hline $\begin{array}{l}\text { 10-Yr-Forward Citations } \\
\text { Including Univ. }\end{array}$ & $\begin{array}{c}.3^{* *} \\
(0.15)\end{array}$ & $\begin{array}{l}.3^{* *} \\
(0.15)\end{array}$ & $\begin{array}{l}.62^{* * *} \\
(0.17)\end{array}$ & $\begin{array}{l}.28^{* *} \\
(0.14)\end{array}$ & $\begin{array}{l}.42^{* *} \\
(0.18)\end{array}$ & $\begin{array}{c}.23 \\
(0.17)\end{array}$ & $\begin{array}{l}.71^{* * *} \\
(0.25)\end{array}$ & $\begin{array}{c}.08 \\
(0.16)\end{array}$ & $\begin{array}{c}.39 \\
(0.25)\end{array}$ & $\begin{array}{c}.15 \\
(0.24)\end{array}$ \\
\hline
\end{tabular}

Note:The table computes Average Citations of Citing Patents computing the 5-years-forward citations of the citing patents and re-classifying university patents as public patents. The table reports differences in citation patterns using two sample t-tests with unequal variances. One star denotes significance at the $10 \%$ level, two stars denote significance at the $5 \%$ level, and three stars denote significance at the $1 \%$ level

distinct 1-digit SIC activities in which a firm operates but extends to finer SIC classifications. All results are presented in Table 14.

Confounding Factors Columns (1) and (2) check robustness of the results with respect to confounding factors. Column (1) estimates the model only allowing for year and organization fixed effects, whereas column (2) includes a set of potential confounding factors. Results in column (1) suggest that presence in an additional industry, not accounting for other variables such as size, is associated on average with a 1.4 percentage-point higher basic research intensity of firms. In column (2) the set of regressors includes controls for size, profitability and headquarter localization. The impact of multiindustry presence is slightly lower but remains statistically significant. ${ }^{17}$ Estimates on the localization of headquarters are also statistically significant at the $5 \%$ level. Total employment and profitability on the other hand are not.

Measures of Multi-Industry Presence Columns (3) and (4) provide alternative measures for the multi-industry presence of firms. Column (3) defines multi-industry presence on the basis of a firm's technological spectrum. To do so we use EPO patent data for French applicants. We define as the number of technology classes in which a firm is present as the cumulative distinct patent classes granted to the firm between 1993 and $t$. The coefficient is very similar in magnitude and precision to the one obtained using distinct 1-digit SIC industries. Column (4) measures multi-industry presence as a weighted sum of all distinct bilateral 1-digit SIC links within firm $i$ in year $t$ considering only distinct legal entities linked by majority ownership. Weights are computed on the basis of the empirical frequency of each bilateral SIC link in each year $t$. Intuitively, if a given bilateral industry link is rare, then industries are more likely to be very different. Multi-industry presence is still positively related to basic research intensity, the different point estimate being linked to the different support of the weighted industry variable.

Causality and Instrumental Variables Columns (5) and (6) address the potential concern of reverse causality, i.e. basic research leading to a larger economic scope of firms. We exploit historical ownership structures that affected a firm's multi-industry presence as instrumental variables. The two instruments are defined as State Ownership 1985-1987 and State Owned between 1985-1987.

The rationale behind our identification strategy is as follows. In 1981 Francois Mitterrand was elected president of the Republic and implemented a vast nationalization program across industries. Even before that period the tradition of French state intervention resulted in a significant fraction of the economy being under state control. Consistent with Colbertist policies, the state also modified the economic scope of its firms by merging unrelated firms into large conglomerates of national champions. In 1987, however, Jacques Chirac was elected prime minister on a liberal platform and this marked the beginning of privatizations, which continued into the 90s. The embedded exclusion restriction

\footnotetext{
${ }^{17}$ Further checks on control variables included market shares, R\&D subsidies, collaborations with universities, the presence of financial intermediaries, state in the capital of the firm, industry fixed effects and the use of a mean patent scaling method.
} 
Table 14: Basic Research Intensity and Multi-Market Activity, Robustness Checks

\begin{tabular}{|c|c|c|c|c|c|c|c|c|}
\hline & \multicolumn{2}{|c|}{ Covariates } & \multicolumn{2}{|c|}{ Alternative Measures } & $\begin{array}{l}\text { Instrumental } \\
(5)\end{array}$ & $\begin{array}{c}\text { Variables } \\
\text { (6) }\end{array}$ & \multicolumn{2}{|c|}{ Estimation } \\
\hline & $\begin{array}{l}(1) \\
\text { No }\end{array}$ & $\begin{array}{l}(2) \\
\text { Yes }\end{array}$ & $\begin{array}{c}(3) \\
\text { Patent } \\
\text { Based }\end{array}$ & $\begin{array}{l}(4) \\
\text { Weighted } \\
\text { Links }\end{array}$ & $\begin{array}{c}(5) \\
\text { State Present } \\
\text { in } 1986\end{array}$ & $\begin{array}{c}(6) \\
\text { SOE } \\
\text { in } 1986\end{array}$ & $\begin{array}{c}(7) \\
\text { Heckman }\end{array}$ & $\begin{array}{c}(8) \\
\text { Negative } \\
\text { Binomial }\end{array}$ \\
\hline \# of Industries & $\begin{array}{c}0.014^{* * *} \\
(0.00)\end{array}$ & $\begin{array}{c}0.011^{* * *} \\
(0.00)\end{array}$ & $\begin{array}{c}0.012^{* * *} \\
(0.00)\end{array}$ & $\begin{array}{c}0.028^{* * *} \\
(0.01)\end{array}$ & $\begin{array}{c}0.023^{* * *} \\
(0.01)\end{array}$ & $\begin{array}{c}0.020^{* *} \\
(0.01)\end{array}$ & $\begin{array}{c}0.045^{* * *} \\
(0.01)\end{array}$ & $\begin{array}{c}0.007^{* * *} \\
(0.00)\end{array}$ \\
\hline Log Employment & & $\begin{array}{c}0.002 \\
(0.00)\end{array}$ & $\begin{array}{c}0.003 \\
(0.00)\end{array}$ & $\begin{array}{c}0.018^{* * *} \\
(0.01)\end{array}$ & $\begin{array}{c}-0.003 \\
(0.00)\end{array}$ & $\begin{array}{r}-0.002 \\
(0.00)\end{array}$ & $\begin{array}{c}0.012^{* * *} \\
(0.00)\end{array}$ & $\begin{array}{r}-0.001 \\
(0.00)\end{array}$ \\
\hline Foreign HQ & & $\begin{array}{c}-0.010^{* *} \\
(0.01)\end{array}$ & $\begin{array}{r}-0.010 \\
(0.01)\end{array}$ & $\begin{array}{c}-0.048^{* *} \\
(0.02)\end{array}$ & $\begin{array}{c}-0.004 \\
(0.01)\end{array}$ & $\begin{array}{l}-0.005 \\
(0.01)\end{array}$ & $\begin{array}{c}-0.041^{* * *} \\
(0.01)\end{array}$ & $\begin{array}{c}-0.006 \\
(0.00)\end{array}$ \\
\hline Profitability & & $\begin{array}{c}0.006 \\
(0.00)\end{array}$ & $\begin{array}{c}0.016 \\
(0.01)\end{array}$ & $\begin{array}{c}0.005 \\
(0.01)\end{array}$ & $\begin{array}{l}0.005 \\
(0.00)\end{array}$ & $\begin{array}{l}0.005 \\
(0.00)\end{array}$ & $\begin{array}{c}0.025^{* *} \\
(0.01)\end{array}$ & $\begin{array}{c}0.005 \\
(0.00)\end{array}$ \\
\hline Year \& Organization FE & YES & YES & YES & YES & YES & YES & YES & YES \\
\hline $\mathrm{N}$ & 13708 & 13706 & 3709 & 14823 & 13707 & 13707 & 13707 & 13707 \\
\hline
\end{tabular}

Notes: Pooled data for the period 2000-2006. Basic Research Intensity is defined as the ratio of total firm investment in basic research divided by total firm investment in applied research. Columns 1 and 2 re-estimate the Tobit model with different sets of regressors. Columns 3 and 4 modify the measure of a firm's multi-industry presence. Column 3 uses patent applications of French firms to the European patent office (1993-2003) to count the number of distinct technological fields in which they are present (1-digit IPC classification). Column 4 weights each bilateral industry link of a firm by the empirical frequency of this link in the French economy, thus giving more weight to less related industries. Columns 5 and 6 re-estimate the model by instrumenting contemporary multi-industry presence by historical ownership structures. More specifically, we exploit the nationalization wave of the Mitterrand era that preceded the privatization of the 90s. The idea is that state ownership effectively increased the scope of a firm's economic activities. Column 5 uses state participation in the capital of a firm in 1986 as an instrument. Column 6 uses state ownership of a company in 1986 as an instrument. Both instruments accurately predict an increased multi-industry presence nowadays. Columns 7 and 8 estimate the relationship between multi-industry presence and basic research intensity by using a Heckman model and a negative binomial model. Tobit estimates relate to the marginal effect of the regressors with respect to the uncensored variable mean and are evaluated at the sample mean of covariates (except for categorical variables evaluated for firms that are present in 1 industry, non-foreign owned, in 2002). Robust standard errors clustered at the firm level in parentheses. See Appendix B for the definition of variables.

therefore requires that state control in the 80 be associated today with a greater basic research intensity of firms only because of politically motivated mergers. The implicit assumption is that when these firms became private they adjusted their research spending from the social to the private optimum but did not adjust their multi-industry presence. First-stage estimates show that state ownership in the $80 \mathrm{~s}$ is associated on average with 1.2 more industry links for firms between 2000 and 2006. The associated F-test are well above the critical levels related to weak instruments tables. ${ }^{18}$ Columns 5 and 6 present the instrumented LATE coefficients related to multi-industry presence of the second stage. The coefficients are nearly twice as large in magnitude with respect to the non-instrumented coefficients of columns 1 and 2 .

Estimation Columns (7) and (8) use alternative estimation methods for the baseline model with covariates. Column (7) presents estimates of the Heckman selection model, whereas column (8) presents estimates from a negative binomial model. In both cases estimates suggest a positive and statistically significant relation between basic research intensity and multi-industry presence.

\footnotetext{
${ }^{18}$ The tables are available upon request.
} 


\section{E Identification: Target Moments and Parameter Sensitivity}

In this section, we provide a sensitivity analysis. In particular, in Table 15 we report the percentage change in the moment (row) for a $5 \%$ change in the parameter (column) from its baseline value, while keeping the rest of the parameters at their benchmark values. We report the average of the $+5 \%$ and $-5 \%$ changes. Therefore, these values can be interpreted as a double-sided discrete approximation.

TABle 15: Jacobian Matrix for Parameter Estimation

\begin{tabular}{|c|c|c|c|c|c|c|c|c|c|c|c|c|c|c|c|c|c|}
\hline Parameter: & $\delta$ & $\gamma$ & $\varepsilon$ & $p$ & $\eta$ & $\bar{\lambda}$ & $E$ & $U$ & $\nu_{a}$ & $\nu_{b}$ & $\xi_{a}$ & $\xi_{b}$ & $\kappa$ & $\bar{\phi}$ & $\sigma$ & $\zeta$ & $\varsigma$ \\
\hline \multicolumn{18}{|l|}{ Moment: } \\
\hline Basic extensive $m=1$ & -1 & -1 & -6 & 0 & 14 & -9 & -4 & 1 & -12 & 64 & 33 & -26 & -0 & 88 & 4 & 1 & -0 \\
\hline Basic extensive $m=2$ & -1 & -1 & -5 & 1 & 13 & -8 & -4 & 1 & -11 & 59 & 31 & -25 & -0 & 81 & 3 & 1 & -0 \\
\hline Basic extensive $m=3$ & -1 & -1 & -5 & 1 & 12 & -8 & -4 & 1 & -11 & 54 & 29 & -24 & -0 & 74 & 2 & 1 & -0 \\
\hline Basic extensive $m=4$ & -1 & -1 & -5 & 2 & 11 & -8 & -3 & 1 & -10 & 50 & 27 & -23 & -0 & 68 & 2 & 1 & -0 \\
\hline Basic extensive $m=5$ & -1 & -1 & -5 & 2 & 11 & -7 & -3 & 1 & -10 & 45 & 25 & -22 & -0 & 62 & 1 & 1 & -0 \\
\hline Basic extensive $m=6$ & -1 & -1 & -4 & 2 & 10 & -7 & -3 & 0 & -9 & 42 & 23 & -20 & -0 & 56 & 1 & 1 & -0 \\
\hline Basic extensive $m=7$ & -1 & -1 & -4 & 3 & 9 & -6 & -3 & 0 & -9 & 38 & 21 & -19 & -0 & 51 & 0 & 0 & -0 \\
\hline Basic extensive $m \geq 8$ & -1 & -1 & -4 & 3 & 8 & -6 & -3 & 0 & -8 & 34 & 19 & -18 & 0 & 45 & -0 & 0 & -0 \\
\hline Basic intensive $m=1$ & -1 & -1 & -2 & 0 & 18 & -11 & -3 & 1 & -15 & 88 & 45 & -32 & -0 & 82 & 3 & 1 & -0 \\
\hline Basic intensive $m=2$ & -1 & -1 & -2 & 1 & 17 & -10 & -3 & 1 & -14 & 81 & 43 & -31 & -0 & 74 & 3 & 1 & -0 \\
\hline Basic intensive $m=3$ & -1 & -1 & -1 & 2 & 16 & -10 & -3 & 1 & -14 & 75 & 41 & -30 & -0 & 68 & 2 & 1 & -0 \\
\hline Basic intensive $m=4$ & -1 & -1 & -1 & 2 & 16 & -10 & -3 & 1 & -13 & 70 & 38 & -29 & -0 & 61 & 1 & 1 & -0 \\
\hline Basic intensive $m=5$ & -1 & -1 & -1 & 3 & 15 & -9 & -3 & 1 & -12 & 65 & 36 & -27 & -0 & 55 & 1 & 1 & -0 \\
\hline Basic intensive $m=6$ & -1 & -1 & -1 & 3 & 14 & -9 & -2 & 1 & -12 & 60 & 34 & -26 & -0 & 50 & 0 & 1 & -0 \\
\hline Basic intensive $m=7$ & -1 & -1 & -0 & 4 & 13 & -8 & -2 & 1 & -11 & 56 & 32 & -25 & -0 & 45 & -0 & 1 & -0 \\
\hline Basic intensive $m \geq 8$ & -1 & -1 & -0 & 4 & 12 & -8 & -2 & 1 & -11 & 50 & 30 & -24 & 0 & 39 & -1 & 1 & -0 \\
\hline Mean $m$ & -0 & -0 & 0 & 0 & 0 & -0 & -1 & 0 & -0 & 0 & 0 & -0 & -0 & 0 & -0 & 0 & 0 \\
\hline Mean $m^{2}$ & -1 & -0 & -0 & 0 & 0 & -0 & -1 & 0 & -1 & 1 & 0 & -1 & -0 & 1 & -0 & 0 & 4 \\
\hline Return on sales & 6 & 3 & -25 & 2 & -9 & 7 & 5 & 2 & 4 & -21 & -8 & 9 & 1 & -20 & 0 & 3 & 9 \\
\hline Exit Rate & -1 & -1 & -4 & 0 & -0 & 0 & 1 & -0 & 3 & -0 & -4 & 0 & 1 & -0 & -0 & -0 & 1 \\
\hline R\&D/labor & -1 & -1 & 6 & -1 & 5 & -0 & -0 & -0 & -0 & 9 & 3 & -3 & -1 & 9 & -0 & -0 & -2 \\
\hline Employment growth & 7 & 10 & 2 & -2 & 3 & 8 & 1 & 2 & 13 & 0 & 15 & 1 & 0 & 15 & 9 & 5 & 10 \\
\hline Aggregate growth & -1 & -1 & -3 & 0 & 2 & 4 & 0 & -0 & 2 & 4 & -2 & -2 & -0 & 4 & 0 & -0 & -0 \\
\hline Spillover differential & 0 & 0 & 0 & -0 & -0 & 0 & 0 & -0 & 0 & -2 & -1 & 1 & 0 & -2 & -0 & -5 & 0 \\
\hline Age, small firms & -0 & 1 & 4 & 1 & 0 & 0 & -3 & 1 & -1 & 0 & 3 & 0 & -1 & 1 & -0 & 0 & 3 \\
\hline Age, large firms & 0 & -1 & 3 & -0 & 1 & -1 & -3 & -0 & -4 & 2 & 5 & -2 & -0 & 1 & 0 & -0 & 2 \\
\hline
\end{tabular}

Note: All values are in percentage terms. 